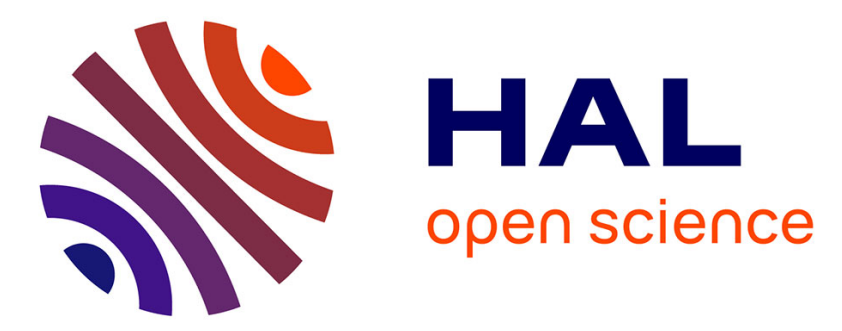

\title{
Modelisation of chloride reactive transport in concrete including thermodynamic equilibrium, kinetic control and surface complexation
}

\author{
van Quan Tran, Anthony Soive, Véronique Baroghel-Bouny
}

\section{To cite this version:}

van Quan Tran, Anthony Soive, Véronique Baroghel-Bouny. Modelisation of chloride reactive transport in concrete including thermodynamic equilibrium, kinetic control and surface complexation. Cement and Concrete Research, 2018, 110, pp.70-85. 10.1016/j.cemconres.2018.05.007 . hal-01865242

\author{
HAL Id: hal-01865242 \\ https://hal.science/hal-01865242
}

Submitted on 4 Jan 2022

HAL is a multi-disciplinary open access archive for the deposit and dissemination of scientific research documents, whether they are published or not. The documents may come from teaching and research institutions in France or abroad, or from public or private research centers.
L'archive ouverte pluridisciplinaire HAL, est destinée au dépôt et à la diffusion de documents scientifiques de niveau recherche, publiés ou non, émanant des établissements d'enseignement et de recherche français ou étrangers, des laboratoires publics ou privés.

\section{(ㄷ)(1) $\$$}

Distributed under a Creative Commons Attribution - NonCommerciall 4.0 International 


\title{
Modelisation of chloride reactive transport in concrete including thermodynamic equilibrium, kinetic control and surface complexation
}

\author{
Van Quan Tran ${ }^{\mathrm{a}}$, Anthony Soive ${ }^{\mathrm{b}, *}$, Véronique Baroghel-Bouny ${ }^{\mathrm{c}}$ \\ a Institute For Hydraulic Construction, No. 54 Trieu Khuc Street, Thanh Xuan District, Hanoi, Vietnam \\ b Cerema, UMR 7329 GEOAZUR, Pôle d'activités, avenue Albert Einstein CS 70499, Aix-en-Provence cedex 3 13593, France \\ c Paris-Est University, IFSTTAR, MaSt/FM2D, Marne-la-Vallée F-77447, France
}

\begin{abstract}
In this study, a new physically and chemically based model taking into account thermodynamic equilibrium, kinetics and surface complexation is proposed to predict the ingress of chloride ions into saturated concretes. The numerical results of this multi-ionic model are compared to experimental data such as total and free chloride concentration profiles and chloride binding isotherms. With only one set of parameters, the results show very good agreement for chloride binding isotherm of concretes with different $w / b$, types of binders (CEM I, CEM III, and CEM I with fly ash) and various exposure conditions ( $\mathrm{NaCl}$ solution at different concentrations). Such a model overcomes the use of empirical chloride binding isotherms that can be difficult to asses for concretes with supplementary cementitious materials. The very good results underline the need to take into account all the physical and chemical phenomena included in the model.
\end{abstract}

\section{Introduction}

The main cause of deterioration for reinforced concrete structures exposed to marine environments is corrosion induced by chloride penetration into concrete. Owing to the expensive costs of maintenance and repair there is a great demand for reliable models designed to predict chloride ingress and its consequences in term of corrosion.

Furthermore, a number of authors consider that the initiation stage of corrosion depends on a chloride threshold value which can be expressed in different forms, such as total chloride content relative to the weight of cement (or concrete) [1], free chloride content [2] and the commonly-used ratio $\left[\mathrm{Cl}^{-}\right] /\left[\mathrm{OH}^{-}\right]$[3-5]. However, all of these descriptions are dependent not only on the propagation of the aggressive solution in the concrete but also on physicochemical reactions such as mineral dissolution/precipitation, sorption/desorption onto mineral surface and aqueous complexation reactions. A reactive transport model could take into account all of these mechanisms.

A number of chloride transport models can be found in the literature, such as models based on Fick's second law or multispecies ionic transport equations [6-8], or physically and chemically coupled model [9]. These models use global binding isotherms to determine total chloride amounts as a function of free chloride amounts. However, the parameters of these isotherms need to be calibrated directly with experimental data [7]. These parameters can also be deducted from the
$\mathrm{C}_{3} \mathrm{~A}$ content [10] or from the $\mathrm{C}_{3} \mathrm{~A}_{e q}$ and C-S-H content ([11] for example). However, in all cases, the parameters are specific to each concrete or to each type of cement. Using physically and chemically based model, Elakneswaran et al. [12] proposed to describe the adsorption of chloride ions more accurately. In their model, the mineral dissolution/precipitation of species in hydrated cement paste is firstly simulated by thermodynamic equilibrium in coupled reactive transport equations. Furthermore, the model takes into account the "physical" adsorption (or sorption/desorption onto a mineral surface) by a surface complexation model. This model describes binding of the ions on the mineral surface assumed as C-S-H. Elakneswaran et al. [12] successfully predicted the total chloride concentration profile in the case of sample exposed to artificial seawater for 91 days at $20^{\circ} \mathrm{C}$.

A number of reactive transport models is proposed in the literature to predict the durability of cementitious materials in chloride environments [13] or sulfate environment [14-19]. The authors assume that the various cement hydrates are in thermodynamic equilibrium. Assuming thermodynamic equilibrium implies that the chemical reaction is instantaneous. Consequently, the mineral species transform immediately [12,16,18-20]. However, taking into account mineral dissolution/precipitation kinetics seems to have a significant influence [21-23].

To the authors' knowledge, a coupled thermodynamic equilibrium/ kinetic and surface complexation has not been proposed to predict the

\footnotetext{
"Corresponding author.

E-mail address: anthony.soive@cerema.fr (A. Soive).
} 
ingress of chloride ions into concrete with different $w / b$, types of binders, incorporation of supplementary cementing materials (SCMs) and exposure to various $\mathrm{NaCl}$ solution concentration. Therefore, in this paper a model including thermodynamic equilibrium, kinetic control and surface complexation is proposed. The model requires only one parameter (sorption density), whose value is the same for all concretes investigated (mixed with CEM I, CEM III or fly ash). The numerical results are firstly compared to experimental chloride binding isotherms. Two approaches for the mineral dissolution/precipitation - thermodynamic equilibrium (TE) and thermodynamic/kinetic (TK) - are then investigated. In TE, the reaction of all solid species is assumed to be instantaneous. The dissolution of some solid species is governed by kinetic laws in TK. The numerical total and free chloride concentration profiles are finally compared to experimental profiles.

In this paper, the first section depicts the governing equations used in the proposed reactive transport model in saturated cementitious materials, such as transport equations, surface complexation onto a mineral surface descriptions, the principle of thermodynamic equilibrium and kinetic laws. The second section introduces the input data of the model: parameters of solid species under kinetic constraint, parameters of surface complexation, initial mineralogical composition of the material, exposure conditions and numerical procedure. A sensitivity study of surface complexation parameter is carried out in order to calibrate the parameter in the third section. Model results are then compared to experimental data taken from [11] and discussed in the last section of the paper.

\section{Description of the reactive transport model}

\subsection{Transport equations}

In a saturated environment without convection phenomena, ion transport is governed by diffusion. Therefore, the principle of mass balance equation can be written in a general form in one-dimension model:

$\frac{\partial M_{j}}{\partial t}=-\frac{\partial J_{j}}{\partial x}+q_{j}$

$M_{j}, J_{j}$ and $x$ denote the molar accumulation of species $j$ in the aqueous phase (mol. $\mathrm{m}^{-3}$ of material), the flux of species $j$ in solution $\left(\mathrm{mol} \cdot \mathrm{m}^{-2} \cdot \mathrm{s}^{-1}\right.$ ) and the distance of diffusion (m), respectively. The $q_{j}$ source or sink of species $\left(\mathrm{mol} \cdot \mathrm{m}^{-3} \cdot \mathrm{s}^{-1}\right)$ is interpreted by the removing or the releasing of species $j$ through physical adsorption onto C-S-H surface (see Paragraph 2.2) $q_{j, C-S-H}$, mineral dissolution/precipitation $q_{j, s}$ and aqueous complexation in solution $q_{j, l}$.

Therefore, the source or sink of species is described as:

$q_{j}=q_{j, C-S-H}+q_{j, s}+q_{j, l}$

In porous media, considering the ionic interactions are taken into account in the source term, the flux of a species $j, J_{j}$, can be described by the first Fick's law:

$J_{j}=-D_{e} \frac{\partial C_{j}}{\partial x}$

$D_{e}=\tau \phi D_{j, w}$

where $D_{e}$ is the effective diffusion coefficient of species $j\left(\mathrm{~m}^{2} \cdot \mathrm{s}^{-1}\right), \tau$ the tortuosity of the porous medium, $\phi$ the bulk porosity, $D_{j, w}$ the free water diffusion coefficient of species $j\left(\mathrm{~m}^{2} \cdot \mathrm{s}^{-1}\right) . C_{j}$ denotes the molar concentration of free species $j$ in a pore solution $\left(\mathrm{mol} \cdot \mathrm{dm}^{-3}\right.$ of solution). In this study as in other studies or software [25-30], the effective diffusion coefficient is assumed to be the same for all species, in particular for primary species that are accounted for in the transport step $\left(\mathrm{Cl}^{-}, \mathrm{SO}_{4}^{2-}, \mathrm{Al}^{3+}, \mathrm{Na}^{+}, \mathrm{K}^{+}\right)$. The diffusion coefficients are assumed to be independent of composition and should be identical to maintain the consistency of model when the classical Fick's law is used. The velocity of the primary species is then the same. That implies zero current in this step. This method has the benefit of improving the calculation speed which can be important in order to study durability of lot of structures with different concretes. Of course, the main drawback of such a strong hypothesis is that it is unavailable when applying an electrical current on the sample boundary. In addition, as captured in geochemical transport codes at the present time, an electrical current typically arises due to the diffusion of charged species at different rates. Here again, the model is not able to catch this effect. Nevertheless, the model focuses on the chemical part of the reactive transport phenomenon taking into account electrical double layer, ionic complexation and dissolution and precipitation of solid species (with kinetics).

In fact, Fick's law is a strictly phenomenological relationship that is more rigorously treated with the Poisson-Nernst-Planck equation [31]. Several studies on reactive transport model that use such a model can be found in the literature (e.g. $[9,16,18])$. The advantage is to ensure charge balance in the transport part. Another way is to assume zero current which leads to a modified coupled Fick's law [24].

According to [31], the mineral dissolution/precipitation leads to bulk porosity reduction as follows:

$\phi=1-\sum_{m=1}^{N_{m}} f r_{m}-f r_{u}$

where $f r_{m}$ is the volume fraction of mineral $\mathrm{m}$ in the medium ( $V$ mineral $/ V$ medium $)$ and $f r_{u}$ is the volume fraction of nonreactive medium. The porosity changes lead to effective diffusion changes.

The molar accumulation of species $j$ is calculated as: $M_{j}=\phi C_{j}$. Therefore, Eq. (1) can be rewritten:

$\frac{\partial \phi C_{j}}{\partial t}=D_{e} \frac{\partial^{2} C_{j}}{\partial x^{2}}+q_{j, C-S-H}+q_{j, s}+q_{j, l}$

It should be noted that the interactions between chemical reactions and transport phenomena are strong since $\phi$ and $D_{e}$ depend on mineral dissolution/precipitation (see Eqs. (4) and (5)).

\subsection{Interaction between solution and $C-S-H$ surface by surface complexation model}

In cementitious materials, the physical adsorption of ions onto the surface of the mineral species of concrete, in particular C-S-H, has been the subject of several studies [34-36]. The surface complexation model describes chemical reaction between the aqueous species and the specific surface sites. The most common surface complexation model is the double diffuse layer model described in detail by Dzombak and Morel [37]. The authors consider that the surface charge density is calculated from the total surface sites of the layer:

$\sigma=F\left[\Gamma_{H}-\Gamma_{O H}+\sum\left(z_{M} \Gamma_{M}\right)+\sum\left(z_{A} \Gamma_{A}\right)\right]$

where $\sigma, F$ and $z_{i}$ denote the surface charge density $\left(\mathrm{C} \cdot \mathrm{m}^{-2}\right)$, the Faraday constant $\left(96,485 \mathrm{C} \cdot \mathrm{mol}^{-1}\right)$ and the valance of sorbing ions $i$, respectively. $\Gamma_{H}, \Gamma_{O H}, \Gamma_{M}$ and $\Gamma_{A}$ are the sorption densities of surface sites $\left(\mathrm{mol} \cdot \mathrm{m}^{-2}\right)$ for protons, hydroxyl, sorbed cations an anions, respectively.

For example, if four kinds of charges in the surface layer are considered $\left(\equiv \mathrm{OH}_{2}^{+}, \equiv \mathrm{OH}, \equiv \mathrm{OM}^{+}, \equiv \mathrm{OA}^{-}\right) \sigma$ is calculated as: 
$\sigma=\frac{F}{A_{c S} S}\left(\left[\equiv \mathrm{OH}_{2}^{+}\right]-[\equiv \mathrm{OH}]+\left[\equiv O M^{+}\right]-\left[\equiv O A^{-}\right]\right)$

where $A_{c s}$ is the specific surface site of the surface complexation model $\left(\mathrm{m}^{2} \cdot \mathrm{g}^{-1}\right)$ and $S$ is the solid concentration $\left(\mathrm{g} \cdot \mathrm{m}^{-3}\right)$. The concentration of surface complexes $\left(\mathrm{mol} \cdot \mathrm{kg}^{-1}\right)$ is represented by the terms in brackets.

For a symmetrical electrolyte with valance $z$, the surface charge density in Gouy-Chapman diffuse layer $\sigma_{d}\left(\mathrm{C} \cdot \mathrm{m}^{-2}\right)$ is related to the potential at the surface $\psi_{0}(\mathrm{~V})$ by:

$\sigma_{d}=\left(8000 R T \varepsilon \varepsilon_{0} c\right)^{\frac{1}{2}} \sinh \left(\frac{z F \psi_{0}}{2 R T}\right)$

where $\mathrm{R}$ is the molar constant $\left(8.354 \mathrm{~J} \cdot \mathrm{mol}^{-1} \cdot \mathrm{K}^{-1}\right), T$ is the absolute temperature $(\mathrm{K}), \varepsilon$ is the relative permittivity of water $(\varepsilon=78.5$ at $\left.25^{\circ} \mathrm{C}\right), \varepsilon_{0}$ is the permittivity of void $\left(8.854 \times 10^{-12} \mathrm{~F} \cdot \mathrm{m}^{-1}\right)$ and $c$ is the molar electrolyte concentration (mol).

The charge balance expression for the double diffuse layer model is:

$\sigma+\sigma_{d}=0$

Therefore, Eq. (11) reads:

$$
\begin{aligned}
& \frac{F}{A_{c S} S}\left(\left[\equiv O H_{2}^{+}\right]-[\equiv O H]+\left[\equiv O M^{+}\right]-\left[\equiv O A^{-}\right]\right) \\
& +\left(8000 R T \varepsilon \varepsilon_{0} c\right)^{\frac{1}{2}} \sinh \left(\frac{Z F \psi_{0}}{2 R T}\right)=0
\end{aligned}
$$

Hence, surface potential is calculated at each chemical equilibrium step as a function of surface complexes concentrations, which are dependent on $\mathrm{pH}$ value.

In concrete, the physical adsorption of ions takes mainly place on the C-S-H surface $[35,38,39]$. Lothenbach et al. [40] used the solid solution model developed by Kulik and Kersten [41] to model the C-S-H phase. Hence, $\mathrm{C}-\mathrm{S}-\mathrm{H}$ is assumed to be a mix of jennite $(\mathrm{CaO})_{1.67}\left(\mathrm{SiO}_{2}\right)$. $\left(\mathrm{H}_{2} \mathrm{O}\right)_{2.1}$ and tobermorite $(\mathrm{CaO})_{0.83}\left(\mathrm{SiO}_{2}\right) \cdot\left(\mathrm{H}_{2} \mathrm{O}\right)_{1.3}$. The number of surface sites depends on the crystal structure of C-S-H. Viallis-Terrisse et al. $[12,35,36]$ considered that the C-S-H surface consisted of only one kind of surface site called silanol $(\equiv \mathrm{SiOH})$. One supplementary site as silandiol $\left(\equiv \mathrm{Si}(\mathrm{OH})_{2}\right.$ ) is rarely considered [42]. Based on the availability of input data in the literature (specific surface area and equilibrium constant), this study assumes that physical adsorption of ions occurs only on the silanol ( $\equiv \mathrm{SiOH}) \mathrm{C}$-S-H surface site.

The C-S-H surface can absorb different cations or anions such as: $\mathrm{Ca}^{2+}, \mathrm{Na}^{+}, \mathrm{K}^{+}, \mathrm{Cl}^{-}$and $\mathrm{SO}_{4}^{2-}[12,43]$. However, the concretes studied here are expose to high concentrations of $\mathrm{Na}^{+}$and $\mathrm{Cl}^{-}$. In addition, Table 6 indicates the presence of low sulfate and high alkaline concentration in the pore solution for all concretes studied. Furthermore, the equilibrium constant of the physicochemical reaction between sulfate and the C-S-H surface has not been measured. Therefore, the surface complexation of sulfate is not considered in this paper.

The adsorption of $\mathrm{Ca}^{2+}, \mathrm{Na}^{+}, \mathrm{K}^{+}$and $\mathrm{Cl}^{-}$ions onto the C-S-H surface layer $(\equiv \mathrm{SiOH})$ can be represented via the sorption reaction, given in Table 1:

At equilibrium, the adsorption of chloride ions onto the surface layer can be described by the mass equation law:

$K_{e q}=\frac{\left[\equiv S i O H C l^{-}\right]}{[\equiv S i O H]\left\{\mathrm{Cl}^{-}\right\}} \exp \left(\frac{-F \psi_{0}}{R T}\right)$

where $K_{e q}$ is the equilibrium constant. $\left\{\mathrm{Cl}^{-}\right\}$is the activity of chloride ions. The equilibrium constant can be measured experimentally. The equilibrium constants of C-S-H are given in Table 1. The equilibrium constants of complexation were extracted from [12] for $\mathrm{Na}^{+}, \mathrm{K}^{+}, \mathrm{Cl}^{-}$and from [35] for $\mathrm{Ca}^{2+}$. The equilibrium constants of
Table 1

Equilibrium constants of surface complexation model.

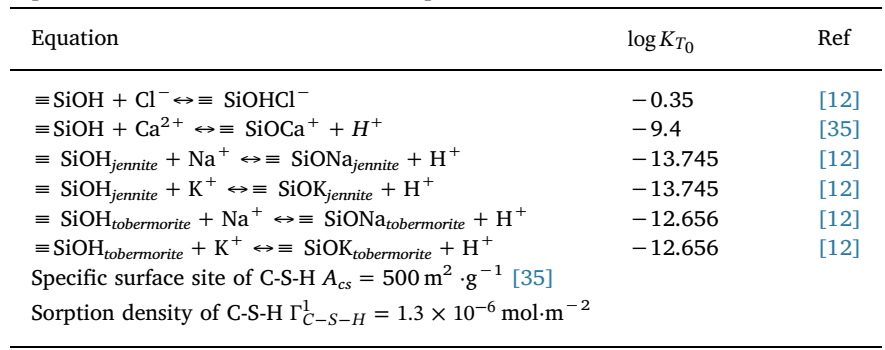

${ }^{1}$ : value deduced from the sensitivity analysis (see Section 4.1.1).

complexation of $\mathrm{Na}^{+}$and $\mathrm{K}^{+}$depend on the C/S ratio of C-S-H. Therefore, the equilibrium constants of adsorption of $\mathrm{Na}^{+}, \mathrm{K}^{+}$onto jennite $(C / S=1.67)$ and tobermorite $(C / S=0.83)$ are different. The equilibrium constants of complexation of $\mathrm{Ca}^{2+}$ and $\mathrm{Cl}^{-}$onto jennite and tobermorite are assumed to be equal.

The equilibrium constant is considered to be constant in the present study since the $\mathrm{pH}$ of the interstitial solution and the $\mathrm{pH}$ of the boundary solutions are very high and close to each other. Hence, the $\mathrm{pH}$ do not vary so much during the experiment.

\subsection{Thermodynamic equilibrium}

If chemical reactions of the mineral dissolution/precipitation or the aqueous complexation are instantaneous, they can be described by the thermodynamic equilibrium laws. In this case the activity of ion $i$ is defined as:

$\left\{A_{i}\right\}=\frac{\gamma_{A_{i}}\left[A_{i}\right]}{\left[A_{0}\right]}$

where $\gamma_{A_{i}}$ is the activity coefficient (dimensionless), $\left[A_{i}\right]$ is the molal concentration of ion $i\left(\mathrm{~mol} \cdot \mathrm{kg}^{-1}\right),\left[A_{0}\right]=1\left(\mathrm{~mol} \cdot \mathrm{kg}^{-1}\right)$ is the molal concentration of an "infinitely dilute solution".

In order to assess the activity coefficient, the true ionic strength $I$ is first required:

$I=\frac{1}{2} \sum_{i}^{N} z_{i}^{2}\left[A_{i}\right]$

where $N$ is the number of species in the solution composed of free species $\left(\mathrm{H}^{+}, \mathrm{OH}^{-}, \mathrm{Ca}^{2+}, \mathrm{Na}^{+}, \mathrm{CO}_{3}^{2-}\right)$ and aqueous complexes $\left(\mathrm{CaOH}^{+}\right.$, $\left.\mathrm{NaCO}^{-}, \ldots\right)$.

In the literature, several approximation equations can be found to calculate the activity coefficient, namely: Debye-Huckel [44], extended Debye-Huckel [45], WATEQ Debye-Huckel [46] and Helgeson-KirhamFlowers (HKF) [47]. The HKF equation can be applied to true ionic strength (see Eq. (14)) up to about 2 molal.

The HKF equation gives accurate activity coefficient when the true ionic strength of the solution is close to 1 with dominance of $\mathrm{NaCl}$ in the solution [27], as in this study. In addition, HKF equation is more suited for solutions where the dominant cation and anion in solution are sodium and chloride, respectively. For other dominant cation and anion although no general rule can be made as to the limit of applicability of the activity coefficient model, using this model at ionic strengths lesser than 3 or 4 is recommended [27]. The HKF equation is then adopted here.

The activity coefficient is calculated as follows: 


$$
\begin{aligned}
\log \left(\gamma_{j}\right)= & \frac{-\xi z_{j}^{2} I^{0.5}}{1+\lambda_{j} \delta \bar{I}^{0.5}}+\log \left(1+0.0180153 m^{*}\right) \\
& -\left[\omega_{j} b_{\mathrm{NaCl}}+b_{N a^{+}, \mathrm{Cl}^{-}}-0.19\left(\left|z_{j}\right|-1\right)\right] I
\end{aligned}
$$

where $\xi=0.5091 \mathrm{~kg}^{0.5} \cdot \mathrm{mol}^{-0.5}$ and $\delta=0.3283 \times 10^{-6} \mathrm{~kg}^{0.5}$. $\mathrm{mol}^{-0.5} \cdot \mathrm{m}^{-1}$ at $p_{0}=1.1013 \times 10^{5} \mathrm{~Pa}$ and $T=25^{\circ} \mathrm{C} \cdot \mathrm{m}^{*}$ is the sum of the molalities of all species in solution $\left(\mathrm{mol} \cdot \mathrm{kg}^{-1}\right)$. Debye-Huckel parameter $\lambda_{j}$ is calculated as:

$\lambda_{j}=\frac{2\left(r_{e, j}+1.91\left|z_{j}\right|\right)}{\left(\left|z_{j}\right|+1\right)} \quad$ for anions

$\lambda_{j}=\frac{2\left(r_{e, j}+1.81\left|z_{j}\right|\right)}{\left(\left|z_{j}\right|+1\right)} \quad$ for cations

where $r_{e, j}$ is the effective ionic radius given in [47] (unit $\AA$ ). $\bar{I}$ is the stoichiometric ionic strength $\left(\mathrm{mol} \cdot \mathrm{kg}^{-1}\right.$ ) calculated by neglecting the contribution of aqueous complexes:

$\bar{I}=\frac{1}{2} \sum_{i}^{M} z_{i}^{2}\left[B_{i}\right]$

where $\left[B_{i}\right]$ is the molal concentration of species $i\left(\mathrm{~mol} \cdot \mathrm{kg}^{-1}\right)$ and $M$ is the number of cations and anions in the solution $(M<N) . \omega_{j}$ is the Born coefficient $\left(\mathrm{J} \cdot \mathrm{mol}^{-1}\right)$ defined as follows:

$\omega_{j}=\eta \frac{z_{j}^{2}}{r_{e, j}}$

with $\eta=6.951218(\AA . \mathrm{J} / \mathrm{mol}) . b_{\mathrm{NaCl}}, b_{\mathrm{Na}^{+}, \mathrm{Cl}^{-}}$are given in [47], at $p_{0}=1.1013 \times 10^{5} \mathrm{~Pa}$ and $T=25^{\circ} \mathrm{C}, b_{\mathrm{NaCl}}=2.47 \times 10^{-3}\left(\mathrm{~kg} \cdot \mathrm{J}^{-1}\right)$ and $b_{\mathrm{Na}^{+}, \mathrm{Cl}^{-}}=-9.770 \times 10^{-2}\left(\mathrm{~kg} \cdot \mathrm{mol}^{-1}\right)$.

The interaction between the ionic species and the mineral species leads to precipitation/dissolution of minerals. The mineral saturation ratio $\Omega_{m}$ can be expressed as:

$\Omega_{m}=K_{s, m}^{-1} \prod_{j=1}^{N_{c}}\left(\gamma_{j} C_{j}\right)^{\nu_{m j}} \quad m=1, \ldots, N_{p}$

where $m$ is the indexes of the mineral species, $K_{s, m}$ is the equilibrium constant, $\nu_{m j}$ is the stoichiometric coefficient of the primary species in the equilibrium, $\gamma_{j}$ is the activity coefficient of the ion $j, C_{j}$ is the molal concentration of primary species in the solution (mol. $\mathrm{kg}^{-1}$ ), $N_{c}, N_{p}$ are the number of corresponding primary species and minerals species.

The state of equilibrium (or disequilibrium) of mineral species in the solution is controlled by the mineral saturation index $I S_{m}$, as follows:

$I S_{m}=\log \Omega_{m}$

For a given mineral species, the solution is in equilibrium with the mineral species if $I S_{m}=0$. The solution is under-saturated and the mineral species can still dissolve if $I S_{m}<0$. Finally, the solution is super-saturated and the mineral species may be precipitated if $I S_{m}>0$.

Aqueous complexes are formed by interactions between primary species in the solution. These reactions are assumed to be at local equilibrium. By using the mass action law, the concentration of aqueous complexes can be expressed as a functions of the concentration of primary species, as follows:

$C_{i}=K_{c, i}^{-1} \gamma_{i}^{-1} \prod_{j=1}^{N_{c}}\left(\gamma_{j} C_{j}\right)^{v_{i j}} \quad i=1, . ., N_{x}$

where $C_{i}$ is the molal concentration of the $i$ aqueous complexes (mol. $\mathrm{kg}^{-1}$ ). $\gamma_{i}$ and $\gamma_{j}$ are the activity coefficients. $K_{c, i}$ is the equilibrium constant of aqueous complexation. $N_{x}$ is the number of aqueous complexes considered in the solution.

\subsection{Kinetic control}

A dimensional analysis focusing on the leaching of calcium hydroxyde in pure water concludes on the validity of a pure thermodynamic approach when transport is diffusion-controlled [48]. Numerical reactive transport results of geochemical interactions at a concrete / argillite interface also show that the mineralogical profiles calculated at thermodynamic equilibrium and with kinetics are very similar after 15 years [49]. On the other hand for concrete exposed for several months the pure thermodynamic approach does not seem to be sufficient $[50,51]$. In addition, the chemical reaction of minerals can be very slow (they may even be irreversible) such as quartz or C-S-H (metastable phase). Furthermore, the kinetic treatment of reactions for those who use reactive transport models is the most general approach [52]. That is the reason why the authors have chosen here to use a kinetic approach.

The kinetic laws adopted in this study follow the expression given by Lasaga et al. [53] for each mineral $n$. This expression is a function of the primary species:

$r_{n}=f\left(C_{1}, C_{2}, \ldots, C_{N_{c}}\right)= \pm k_{n} A_{m s, n}\left|1-\Omega_{n}^{\theta}\right| \eta \quad n=1, . ., N_{q}$

where positive values of $r_{n}$ indicate dissolution and negative values precipitation, $k$ is the rate constant $\left(\mathrm{mol} \cdot \mathrm{m}^{-2} \cdot \mathrm{s}^{-1}\right) . A_{m s}$ is the specific reactive surface area $\left(\mathrm{m}^{2} \cdot \mathrm{g}^{-1}\right), \Omega$ is the mineral saturation ratio defined in (Eq. (21)). When the reaction approaches equilibrium state, $\Omega$ approaches 1 and the chemical reaction rate tends toward zero. The parameters $\theta, \eta$ can be determined from experiments. They are usually taken to be equal to one due to lack of measurement. $q$ is the number of minerals under kinetic constraints.

Details on the solution method for mixed thermodynamic equilibrium/kinetic chemical system are given in $[27,31]$.

\subsection{Charge balance}

The reactive transport and in particular the electrical current can be affected by electrical double layer, ionic complexation and dissolution and precipitation of solid species (with kinetics). All these phenomena leads to charge unbalance. Then, in the chemical step, a computation of the aqueous complexes (secondary species such as $\mathrm{Al}(\mathrm{oh})^{4-}, \mathrm{NaCl}(\mathrm{aq})$, $\mathrm{CaCl}_{2}(\mathrm{aq}), \mathrm{CaOH}^{+}, \mathrm{KSO}_{4}^{-} \ldots$ ), the surface complexation and the chemical reactions between ions and solid species is done. Such a computation implies charge unbalance that is checked by calculating a charge balance error, CBE, for this solution:

$C B E=\frac{\sum_{n}^{C} z_{n} C_{n}-\left|\sum_{m}^{A} z_{m} C_{m}\right|}{\sum_{n}^{C} z_{n} C_{n}+\left|\sum_{m}^{A} z_{m} C_{m}\right|} \times 100$

where $z_{n}, z_{m}, C_{n}, C_{m}, C$ and $A$ are the charge of anion and cation, the concentrations of cations $n$ and anions $m$ for primary and secondary species (mol/l of solution) and the number of cation and anions in the solution, respectively.

The electroneutrality condition is considered as acceptable when $C B E \leq 5 \%$ [54]. If the condition is satisfied, a new transport step follows.

\section{Required input data}

\subsection{Mineralogical compositions of hydrated cement}

The composition of cement minerals is calculated from the system $\mathrm{CaO}-\mathrm{Al}_{2} \mathrm{O}_{3}-\mathrm{SiO}_{2}-\mathrm{SO}_{3}-\mathrm{MgO}$ with the GEMS software and the CEMDATA07 and Nagra/PSI TDB thermodynamic databases [55]. Two 
Table 2

Parameters describing the kinetics of mineral reactions at $25{ }^{\circ} \mathrm{C}$ : dissolution rate constant $k\left(\mathrm{~mol} \cdot \mathrm{m}^{-2} \cdot \mathrm{s}^{-1}\right)$ and mineral specific reactive surface area $A_{m s}\left(\mathrm{~m}^{2}\right.$ $\cdot \mathrm{g}^{-1}$ ). Precipitation mechanism and associated constants are assumed to be similar to dissolution.

\begin{tabular}{llll}
\hline Minerals & $A_{m s}$ & $k$ & Ref \\
\hline Jennite & 41.0 & $2.75 \times 10^{-12}$ & {$[61]$} \\
Tobermorite & 41.0 & $2.75 \times 10^{-12}$ & {$[61]$} \\
Ettringite & 9.8 & $7.08 \times 10^{-13}$ & {$[61]$} \\
Monosulfoaluminate & 5.7 & $6.76 \times 10^{-12}$ & {$[61]$} \\
Portlandite & 16.5 & $2.24 \times 10^{-8}$ & {$[62]$} \\
Hydrotalcite & & Instantaneous & \\
Kuzel's salt & & Instantaneous & \\
Gibbsite & $9.8 \times 10^{-4}$ & $3.16 \times 10^{-12}$ & {$[63]$} \\
\hline
\end{tabular}

thermodynamic databases were also constructed from the standard molar thermodynamic properties of species given by Lothenbach and Winnefeld [56], Matschei et al. [57], Lothenbach et al. [40], Thoenen and Kulik [58]. Lothenbach et al. [40] used the solid solution model developed by Kulik and Kersten [41] to model the C-S-H phase. Hence, $\mathrm{C}-\mathrm{S}-\mathrm{H}$ is supposed here to be a mix of jennite $(\mathrm{CaO})_{1.67}\left(\mathrm{SiO}_{2}\right) \cdot\left(\mathrm{H}_{2} \mathrm{O}\right)_{2.1}$ and tobermorite $(\mathrm{CaO})_{0.83}\left(\mathrm{SiO}_{2}\right) \cdot\left(\mathrm{H}_{2} \mathrm{O}\right)_{1.3}$. Other hydrated cement compounds are portlandite $\mathrm{Ca}(\mathrm{OH})_{2}$, monosulfoaluminate $\mathrm{Ca}_{4} \mathrm{Al}_{2} \mathrm{SO}_{4}(\mathrm{OH})_{12}\left(\mathrm{H}_{2} \mathrm{O}\right)_{6}$, ettringite $\mathrm{Ca}_{6} \mathrm{Al}_{2}\left(\mathrm{SO}_{4}\right)_{3}(\mathrm{OH})_{12}\left(\mathrm{H}_{2} \mathrm{O}\right)_{26}$ and hydrotalcite $\mathrm{Mg}_{4} \mathrm{Al}_{2}(\mathrm{OH})_{14}\left(\mathrm{H}_{2} \mathrm{O}\right)_{3}$.

Looking at the reactions between chloride and hydrated cement and using X-ray powder diffraction (XRPD), Yoon et al. [59] reported that only Kuzel's salt $\mathrm{Ca}_{4} \mathrm{Al}_{2}\left(\mathrm{SO}_{4}\right)_{0.5} \mathrm{Cl}(\mathrm{OH})_{12}\left(\mathrm{H}_{2} \mathrm{O}\right)_{6}$ may precipitate when monosulfoaluminate reacts with chloride ions at a chloride concentrations $<3 \mathrm{M}$. Mesbah et al. [60] also pointed out that even if monosulfoaluminate reacts with chloride ions at high chloride/monosulfoaluminate concentration ratio in the $\mathrm{CaO}-\mathrm{Al}_{2} \mathrm{O}_{3}-\mathrm{CaCl}_{2}-\mathrm{H}_{2} \mathrm{O}$ system, Kuzel's salt is found as well as an intermediate product between monosulfoaluminate and Friedel's salt $\mathrm{Ca}_{4} \mathrm{Al}_{2} \mathrm{Cl}_{1.95}(\mathrm{OH})_{12.05}\left(\mathrm{H}_{2} \mathrm{O}\right)_{4}$. Furthermore, at such a concentration, gibbsite $\mathrm{Al}(\mathrm{OH})_{3}$ may also precipitate when the dissolution of monosulfoaluminate releases $\mathrm{Al}^{3+}$ into the solution. Therefore, Kuzel's salt and gibbsite may appear.

\subsection{Reaction rate and surface complexes parameters}

Matschei et al. [57] reported that the internal constitution of hydrated Portland cements tends to approach thermodynamic equilibrium for all hydrates except for C-S-H when considering the thermodynamic properties of Portland cement hydrates in the system $\mathrm{CaO}-\mathrm{Al}_{2} \mathrm{O}_{3}-\mathrm{SiO}_{2}$ $\mathrm{CaSO}_{4}-\mathrm{CaCO}_{3}-\mathrm{H}_{2} \mathrm{O}$. In the case of $\mathrm{C}-\mathrm{S}-\mathrm{H}$, the dissolution/precipitation (jennite and tobermorite) is controlled by kinetic laws in all cases of investigation given the metastable nature of C-S-H. When concrete is exposed to an aggressive environment the kinetic parameters of all hydrates are needed. Monosulfoaluminate, ettringite and C-S-H reaction rate values are taken from Baur et al. [61]. The values for jennite and tobermorite are assumed to be equal. The reaction rates of portlandite and gibbsite are taken from Gali et al. [62] and Palandri et al. [63], respectively. Due to lack of data, hydrotalcite and Kuzel's salt are assumed to react instantaneously. The kinetic parameters are shown in Table 2.

In a surface complexation model, Viallis et al. [35] proposed a specific surface site of $500 \mathrm{~m}^{2} \cdot \mathrm{g}^{-1}$ for C-S-H in order to obtain the best calibration of the experimental data. This value is higher than the one proposed by Taylor [64] $\left(200 \mathrm{~m}^{2} \cdot \mathrm{g}^{-1}\right)$. However, Viallis et al. [35] and Elakneswaran et al. [39] used this value of specific surface site to deduce the equilibrium constants of physicochemical reaction onto the C-
Table 3

Mix-design in $\mathrm{kg} \cdot \mathrm{m}^{-3}$, main characteristics and effective chloride diffusion coefficients, after $[11,65]$.

\begin{tabular}{lllll}
\hline Concrete & BO & M25 & M30FA & LR-CEM III \\
\hline CEM III & & & & 385 \\
CEM I 1 & 353 & & & \\
CEM I 2 & & 230 & 353 & \\
Fly Ash & & & & 95 \\
Water & 172 & 193 & 172 & 159 \\
w/b = water / (c + SCM) & 0.49 & 0.84 & 0.38 & 0.41 \\
Apparent density & 2292 & 2288 & 2280 & 2340 \\
Porosity accessible to water $\phi(\%)$ & 0.128 & 0.149 & 0.141 & 0.121 \\
Effective chloride diffusion coefficient $D_{e}$ & 1.2 & 9.0 & 0.39 & 0.103 \\
$\quad\left(\times 10^{-12} \mathrm{~m}^{2} \mathrm{~s}^{-1}\right.$ ) & 3 & 9 & 24 & 5 \\
Age of concrete (months) & & & & \\
\hline
\end{tabular}

$\mathrm{S}$-H surface, given in Table 1 . Therefore, the value of $500 \mathrm{~m}^{2} \cdot \mathrm{g}^{-1}$ for the specific surface site of C-S-H is used in this study. Regarding sorption density, Elakneswaran et al. [12] reported that details on the sorption density of C-S-H $\Gamma_{C-S-H}$ and its dependence on the C/S ratio have not been established and that more research is needed on this topic. Therefore, the value of $\Gamma_{C-S-H}$ will be estimated from a parametrical study that will be shown on the next sections.

\subsection{Initial mineralogical composition, pore solution of concrete and boundary conditions}

In this paper, numerical results are compared with experimental data of four concretes (designed as BO, M25, M30FA and LR-CEM III) that were casted and exposed to an immersion test in order to determine the chloride penetration depth and the chloride binding isotherms in saturated conditions at $20^{\circ} \mathrm{C}$ in laboratory conditions [11]. The cylindrical samples (height $=100 \mathrm{~mm}$ and diameter $=110 \mathrm{~mm}$ ) have been exposed after several month water curing and vacuum saturation with a $0.1-\mathrm{M} \mathrm{NaOH}$ solution. Mix-design, main characteristics and effective chloride diffusion coefficients are reported in Table 3. The porosity accessible to water and the apparent density of the dry concrete were measured by hydrostatic weighting at the age of 3 months, 9 months, 2 years and 5 months for BO, M25, M30FA and LR-CEM III, respectively. The effective chloride diffusion coefficients were directly assessed from a steady state migration test. Further details on these experiments are given in $[11,65]$.

Due to the complexity of the approach (hydration + reactive transport) the initial mineralogical composition of the concrete was initially calculated by the thermodynamic equilibrium part of the GEMS-software (and not the hydration one) with CEMDATA07 and Nagra/PSI TDB thermodynamic databases [55]. This implies that the concretes are supposed to be completely hydrated. Input data for GEMS-software is the chemical composition of the cement CEM I 1, CEM I 2, CEM III and fly ash (see Table 5). The initial mineralogical composition of the completely hydrated material resulting from the hydration model is given in Table 4. Presence of $\mathrm{CO}_{2}$ (in the atmosphere or in water) is not taken into account in the calculation. It is worth noting that the number of required input data is very small in this model. Furthermore, the binding isotherms are not required.

However, in the thermodynamic equilibrium calculation by GEMS $\mathrm{Na}+$ an $\mathrm{K}+$ do not have to be taken into account (they influence hydration kinetic). Then, the ionic solution and the $\mathrm{pH}$ computation do not give an accurate result. Therefore, a first computation is performed to obtain the mineral composition of the completely hydrated concrete with GEMS. Then, assuming total dissolution of the alkalis $\mathrm{Na}$ and $\mathrm{K}$ in 
Table 4

Chemical and mineralogical composition of the binder, given in (\%) $[11,65]$.

\begin{tabular}{lllll}
\hline & CEM I 1 & CEM I 2 & Fly Ash & CEM III Gargenville \\
\hline $\mathrm{SiO}_{2}$ & 21.14 & 21.39 & 50.00 & \\
$\mathrm{Al}_{2} \mathrm{O}_{3}$ & 2.86 & 3.49 & 29.00 & \\
$\mathrm{Fe}_{2} \mathrm{O}_{3}$ & 2.25 & 4.16 & 8.50 & \\
$\mathrm{CaO}$ & 67.11 & 65.12 & 3.00 & \\
$\mathrm{MgO}$ & 0.75 & 0.82 & 0.00 & \\
$\mathrm{SO}_{3}$ & 2.10 & 2.86 & 0.5 & 3.3 \\
$\mathrm{~K}_{2} \mathrm{O}$ & 0.14 & 0.3 & 4.5 & \\
$\mathrm{Na}_{2} \mathrm{O}$ & 0.16 & 0.12 & 0.7 & \\
$\mathrm{~S}^{2-}$ & & & & 0.4 \\
$\mathrm{C}_{3} \mathrm{~A}$ & & & & 70.5 \\
$\mathrm{C}_{3} \mathrm{~S}$ & & & & 7.3 \\
$\mathrm{C}_{2} \mathrm{~S}$ & & & \\
\hline
\end{tabular}

Table 5

Amount of mineral species after complete hydration thanks to the thermodynamic equilibrium computation of GEMS software [55].

\begin{tabular}{lllll}
\hline \multirow{2}{*}{ Mineral } & \multicolumn{4}{l}{ Amount $\left(\mathrm{mol} \cdot \mathrm{dm}^{-3}\right.$ of concrete) } \\
\cline { 2 - 5 } & BO & M25 & M30FA & LR-CEM III \\
\hline Jennite & 1.1917 & 0.7178 & 1.7984 & 1.1912 \\
Tobermorite & 0.1677 & 0.1010 & 0.2488 & 0.1675 \\
Ettringite & 0.0050 & 0.0076 & 0 & 0.0256 \\
Hydrotalcite & 0.0164 & 0.0117 & 0.0180 & 0 \\
Portlandite & 1.7581 & 1.1070 & 0.2497 & 1.5987 \\
Monosulfoaluminate & 0.0776 & 0.0595 & 0.1320 & 0.0938 \\
\hline
\end{tabular}

Table 6

Initial composition of pore solution in concrete $\left(\mathrm{mol} . \mathrm{kg}^{-1}\right)$ calculated by Toughreact at $20^{\circ} \mathrm{C}$

\begin{tabular}{lllll}
\hline & BO & M25 & M30FA & LR-CEMIII \\
\hline $\mathrm{Na}^{+}$ & 0.2752 & 0.0728 & 0.0352 & 0 \\
$\mathrm{~K}^{+}$ & 0.1589 & 0.1197 & 0.1136 & 0 \\
$\mathrm{Ca}^{2+}$ & $0.4825 \times 10^{-4}$ & $0.2102 \times 10^{-2}$ & $0.2886 \times 10^{-2}$ & $0.1987 \times 10^{-1}$ \\
$\mathrm{Mg}^{2+}$ & $0.6813 \times 10^{-9}$ & $0.1258 \times 10^{-8}$ & $0.1573 \times 10^{-8}$ & 0 \\
$\mathrm{Al}^{3+}$ & $0.5010 \times 10^{-3}$ & $0.2427 \times 10^{-3}$ & $0.1876 \times 10^{-3}$ & $0.482 \times 10^{-4}$ \\
$\mathrm{HSiO}_{3}^{-}$ & $0.4825 \times 10^{-4}$ & $0.1124 \times 10^{-4}$ & $0.9157 \times 10^{-4}$ & $0.1540 \times 10^{-6}$ \\
$\mathrm{SO}_{4}^{2-}$ & $0.4869 \times 10^{-3}$ & $0.9042 \times 10^{-4}$ & $0.5127 \times 10^{-4}$ & $0.3687 \times 10^{-5}$ \\
$\mathrm{pH}^{13.589}$ & 13.229 & 13.200 & 12.643 \\
\hline & & & &
\end{tabular}

the interstitial solution [66], the equilibrium is performed with the Toughreact software (see the next paragraph for a more precise description). This choice is consistent with the reactive transport part of the simulation (use of Toughreact). It is worth noting that the first computation with Toughreact does not change the amount of the mineral species obtained by GEMS. This emphasizes the compatibility between GEMS and Toughreact softwares. From the amount of cement hydrates given in Table 5 the results are presented in Table 6 .

The chemical composition of the contact solution depends on the exposure conditions. Here, the concrete samples (M25, M30FA, LR-CEM III) are exposed to a $30 \mathrm{~g} \cdot \mathrm{L}^{-1} \mathrm{NaCl}$ solution $\left(+4 \mathrm{~g} \cdot \mathrm{L}^{-1} \mathrm{NaOH}\right)$ for 3 months [11]. The BO concrete is exposed to a $60 \mathrm{~g} \cdot \mathrm{L}^{-1} \mathrm{NaCl}$ solution $\left(+4 \mathrm{~g} \cdot \mathrm{L}^{-1} \mathrm{NaOH}\right)$ for 3 months. As depicted in Table 6 , the $\mathrm{pH}$ value depends on the cement composition. The equilibrium calculation for the contact solution gives $\mathrm{pH}=12.95$. Further details on the $\mathrm{pH}$ calculation are given in [67].

\subsection{Reactive transport modeling}

In the simulations carried out in this paper only saturated concretes are considered. The calculations were performed in 1D. The numerical results are compared to experimental data on cylindrical specimens where a dense epoxy coating was applied to lateral surface and to one plane face, leaving the other plane surface exposed to the solution. This configuration ensures a one dimensional flow inside the cylinders.

A simple mesh composed of one 1000-element row was used and represented $100 \mathrm{~mm}$ of the sample. Such a number of elements has been used in order to be accurate for the thermodynamic approach. As a matter of fact, for transient problems the pure thermodynamic approach is sensitive to the number of elements of the mesh [21] that is to say by the time step of the simulation. In order to compare the thermodynamic approach to the kinetic one, the same number of elements has been chosen. However, in the simple case of taking into account the kinetics, such a great number of elements is not necessary.

The reactive transport code Toughreact [27] was used in order to compute the ingress of chloride ions in the concretes studied. It is an integral finite difference method program for chemically reactive nonisothermal flows of multiphase fluids in porous and fractured media. The software calculations are usually performed with the sequential non-iterative approach (SNIA). It is applicable to a variety of reactive fluid and geochemical transport problems, including contaminant transport, natural groundwater chemistry evolution, assessment of nuclear waste disposal sites, sedimentary diagenesis, and $\mathrm{CO}_{2}$ disposal in deep formations, mineral alteration and silica scaling in hydrothermal systems under natural and production conditions. It has also been used to study concrete durability (e.g. $[21,68])$.

\subsection{Thermodynamic database}

As detailed in the previous sections, the surface complexation model and the thermodynamic equilibrium (aqueous complexation and thermodynamic equilibrium of mineral species) are each described by a reaction expression and its equilibrium constant. According to [69], the equilibrium constants for thermodynamic equilibrium are established from the standard molar thermodynamic properties of reactants and products that depend on the temperature. For surface complexation, the approach is the same. Hence, the thermodynamic database contains the species used, the chemical equations with their related constant value for minerals dissolution/precipitation, aqueous complexation and surface complexation. In this database, the primary species considered are $\mathrm{H}^{+}, \mathrm{Ca}^{2+}, \mathrm{Mg}^{2+}, \mathrm{K}^{+}, \mathrm{Na}^{+}, \mathrm{Al}^{3+}, \mathrm{SO}_{4}^{2-}, \mathrm{HSiO}_{3}^{-}, \mathrm{Cl}^{-}$and $\mathrm{H}_{2} \mathrm{O}$.

The equilibrium constants of mineral dissolution/precipitation and aqueous complexation were calculated from the standard molar thermodynamic properties of species given in [40,56-58] (and [70] for Kuzel's salt). Adopting the same standard molar thermodynamic property values as used in the CEMDATA database gives consistency between the GEMS and the Toughreact calculations. Further details on the construction of the thermodynamic database have been presented in [67]. Furthermore, the physicochemical reaction on a C-S-H surface, given in Table 1, is also integrated into the thermodynamic database.

\section{Results}

\subsection{Validation of the model}

\subsubsection{Sensitivity study of $C-S-H$ sorption density}

The sorption density $\Gamma_{C-S-H}$ is an important parameter in the surface complexation model. The aim of this section is to determine the C-S-H sorption density value for BO concrete. The calculated value will 

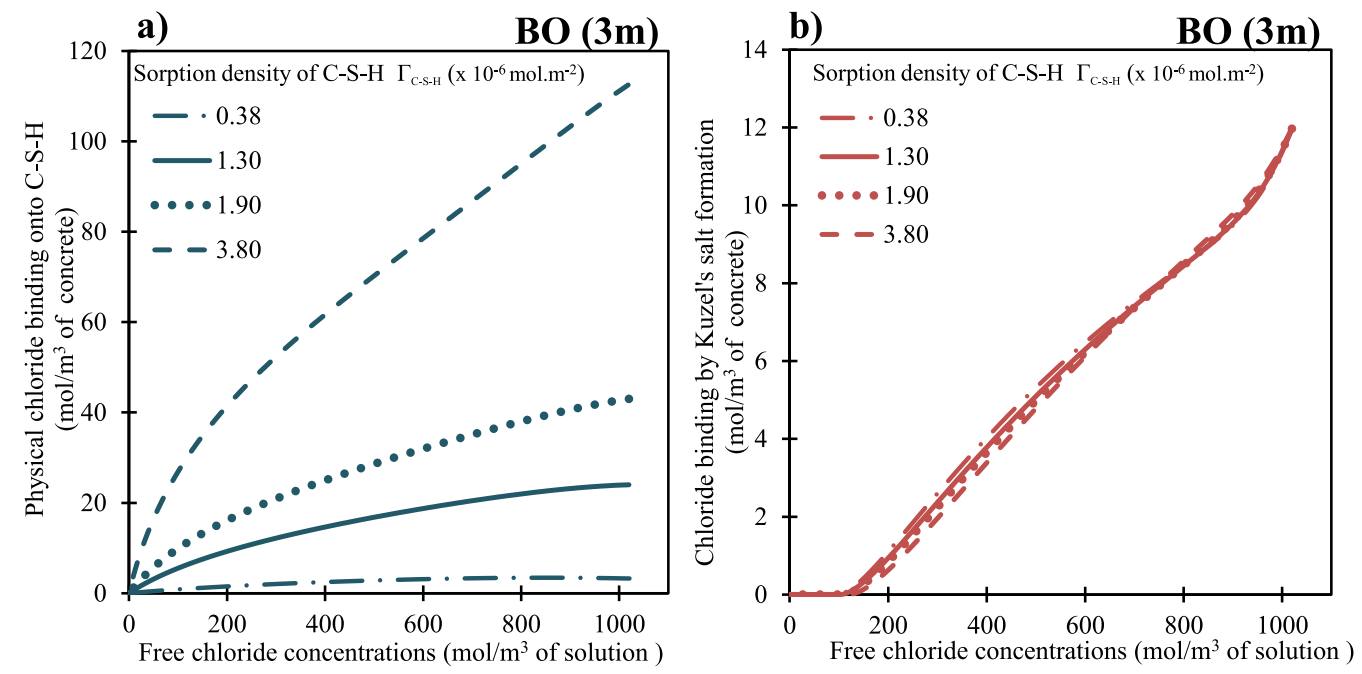

Fig. 1. Sensitivity study of sorption density of C-S-H $\Gamma_{C-S-H}\left(\mathrm{~mol} \cdot \mathrm{m}^{-2}\right)$ of completely hydrated BO after 3 months exposure to $60 \mathrm{~g} \cdot \mathrm{L}^{-1} \mathrm{NaCl}$ solution $\left(+4 \mathrm{~g} \cdot \mathrm{L}^{-1}\right.$ $\mathrm{NaOH}$ ) on a) "Physical" chloride binding onto C-S-H, b) Chloride binding by Kuzel's salt formation.

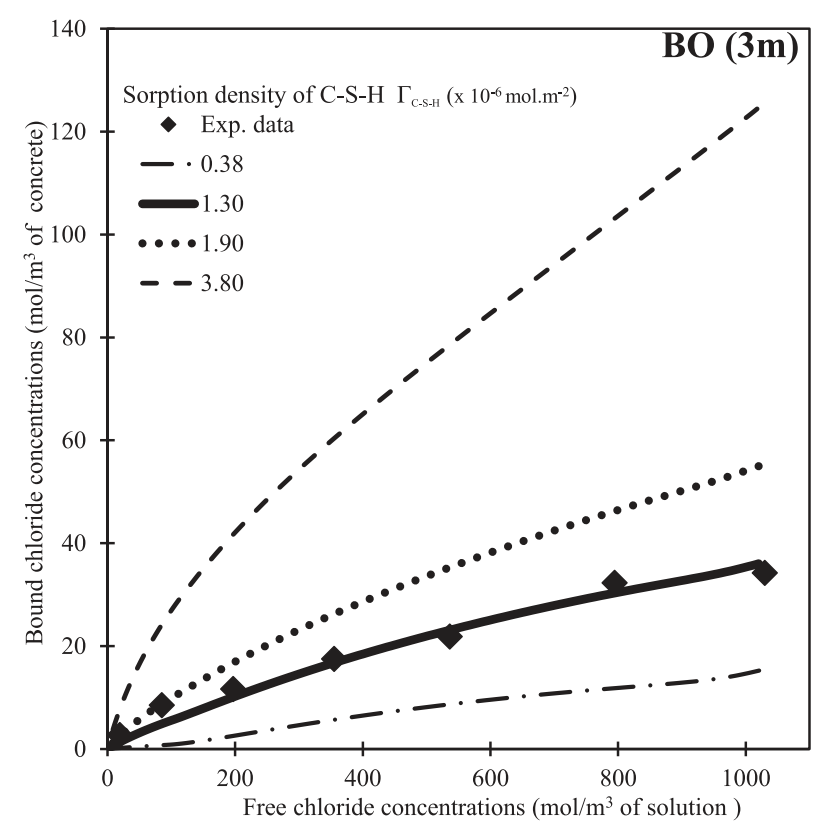

Fig. 2. Sensitivity study of sorption density of $\mathrm{C}-\mathrm{S}-\mathrm{H} \Gamma_{C-S-H}\left(\mathrm{~mol} \cdot \mathrm{m}^{-2}\right)$ on chloride binding isotherm. Experimental data [11] are obtained by the profile method at $20^{\circ} \mathrm{C}$ after 3 -months of exposure to $60 \mathrm{~g} \cdot \mathrm{L}^{-1} \mathrm{NaCl}$ solution $\left(+4 \mathrm{~g} \cdot \mathrm{L}^{-1} \mathrm{NaOH}\right)$.

assume to be the same for the other concretes in this study. Goldberg indicated in [71] that a fixed value of $3.8 \times 10^{-6} \mathrm{~mol} \cdot \mathrm{m}^{-2}$ of sorption density had been used for many natural materials. The TK is assumed to be appropriate to investigate the sorption density sensitivity of C-S-H. Fig. 1a and b show "physical" chloride binding onto C-S-H and chloride binding by Kuzel's salt formation, respectively. "Physical" chloride binding onto C-S-H depends on the sorption density value (see Fig. 1a). On the other hand and as expected the chloride binding by Kuzel's salt formation is relatively independent from the surface complexation model (see Fig. 1a and b, respectively).
Fig. 2 shows the numerical chloride binding isotherm including the "physical" chloride binding onto C-S-H and the chloride binding by Kuzel's salt formation. The numerical chloride isotherm is compared to the experimental chloride binding isotherm [11] obtained by total and free chloride profile measurements after 3 months of exposure to $60 \mathrm{~g} \cdot \mathrm{L}^{-1}$ $\mathrm{NaCl}$ solution $\left(+4 \mathrm{~g} \cdot \mathrm{L}^{-1} \mathrm{NaOH}\right) . \Gamma_{C-S-H}=1.3 \times 10^{-6} \mathrm{~mol} \cdot \mathrm{m}^{-2}$ seems to be the best sorption density value where the TK approach. As a matter of fact, very good agreement with this value can be obtained by comparing numerical and experimental results for this surface complexation model.

Using $\Gamma_{C-S-H}=1.3 \times 10^{-6} \mathrm{~mol} \cdot \mathrm{m}^{-2}$, a sensitivity study on the effective chloride diffusion coefficient and the bulk porosity were carried out. Fig. $3 a$ and $b$ show that the effective chloride diffusion coefficient and the porosity values did not influence the chloride binding isotherm. Therefore, this sorption density value is adopted in next sections.

\subsubsection{Validation of the model by calculating the chloride binding isotherm for various concretes}

The model integrating the TK and the surface complexation and relying on the database previously described uses only one same parameter value (the sorption density value $\Gamma_{C-S-H}=1.3 \times 10^{-6}$ $\mathrm{mol} \cdot \mathrm{m}^{-2}$ ) in order to calculate the chloride binding isotherms of various concretes. Fig. 4a depicts the chloride binding isotherms of M25 after 3- and 5-month exposure to $30 \mathrm{~g} \cdot \mathrm{L}^{-1} \mathrm{NaCl}$ solution $\left(+4 \mathrm{~g} \cdot \mathrm{L}^{-1}\right.$ $\mathrm{NaOH}$ ). In the same conditions of exposure, the chloride binding isotherms of M30FA and LR-CEMIII after 3-month exposure is shown in Fig. 4b. The numerical chloride binding isotherms are compared to the experimental data [11]. The results show that the model can very well predict the chloride binding isotherms without any other parameter derived from experimental measurements (e.g. porosity accessible to water or effective chloride diffusion and apparent density).

\subsection{Thermodynamic equilibrium and thermodynamic kinetic control}

The differences between the TE and the TK models can be underlined on the chloride binding isotherms, evolution of solid phases as well as total chloride and free chloride concentration profiles. The 
a)

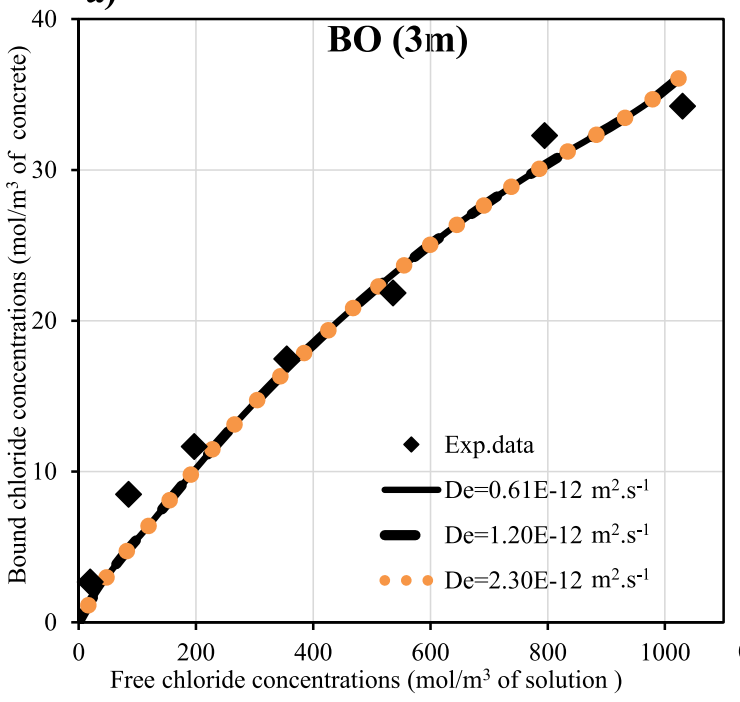

b)

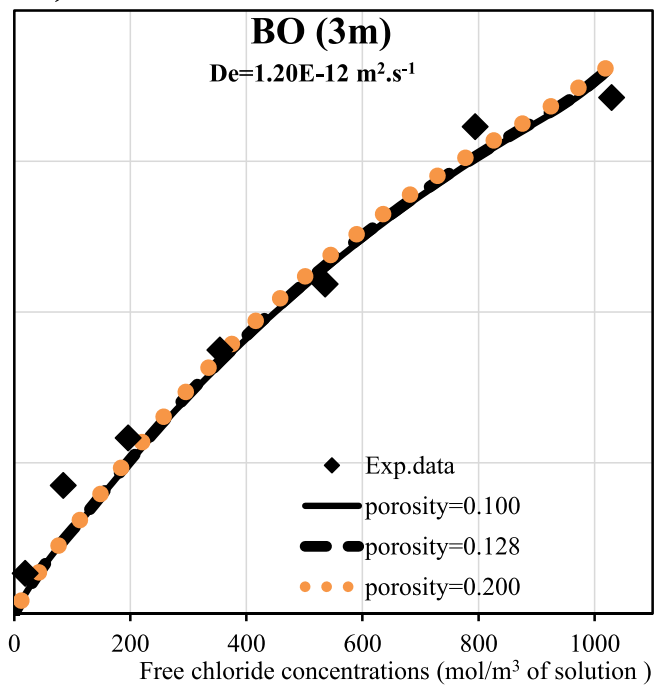

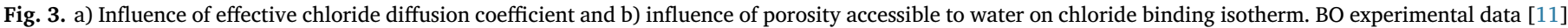
were obtained by the profile method at $20{ }^{\circ} \mathrm{C}$ after 3 months exposure to $60 \mathrm{~g} \cdot \mathrm{L}^{-1} \mathrm{NaCl}$ solution $\left(+4 \mathrm{~g} \cdot \mathrm{L}^{-1} \mathrm{NaOH}\right)$.

a) $M 25$

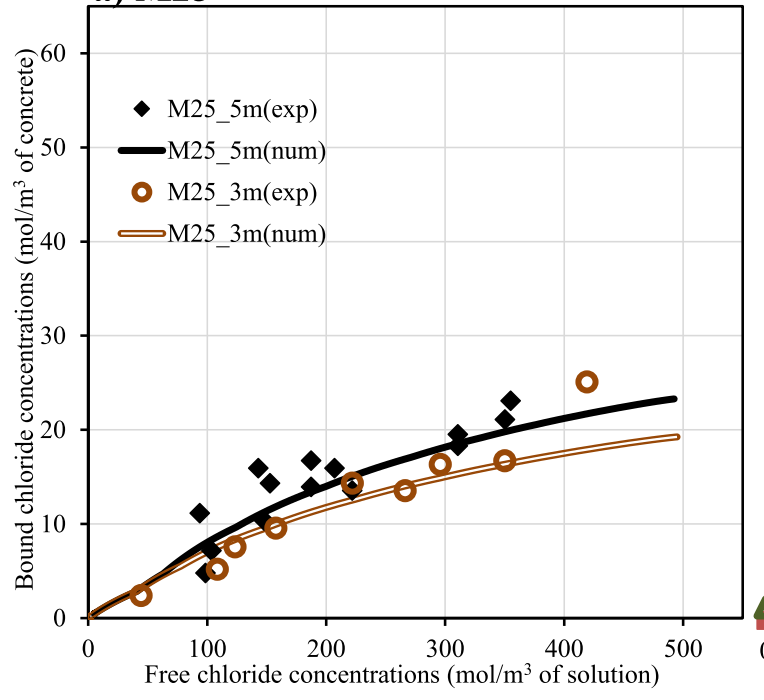

b) M30FA, LR CEM III

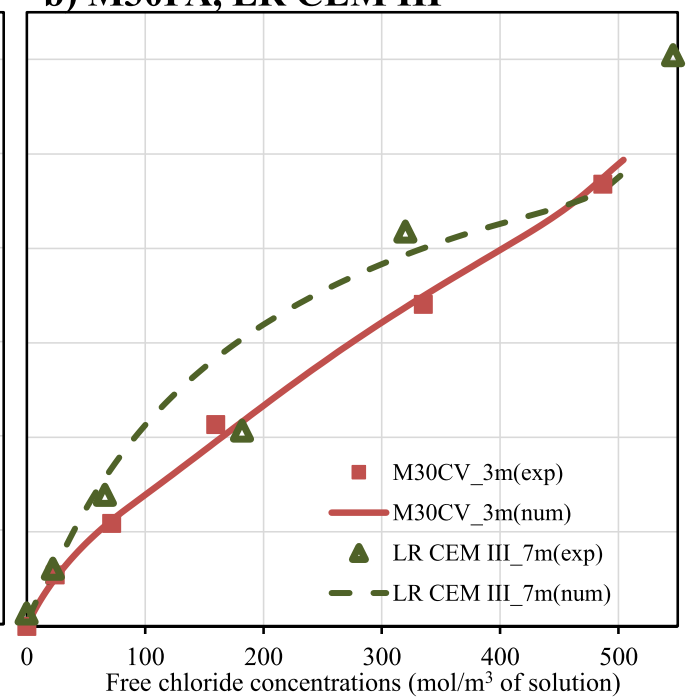

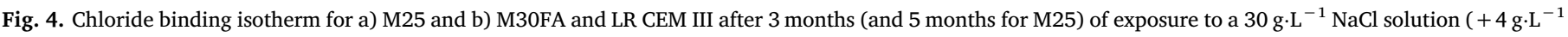
$\mathrm{NaOH})$ at $20^{\circ} \mathrm{C}$. Comparison between simulations and experimental data from the literature [11].

differences can be confirmed through the investigation of four concretes (BO in Figs. 5, 6 and 7, M25 in Figs. 8, 9 and 10, M30FA in Figs. 11, 12 and 13, LR-CEM III in Figs. 14, 15). The numerical chloride binding isotherms are compared to experimental data [11] for the various concretes studied. The numerical chloride concentration profiles are also compared to experimental data [11], except for LR-CEM III where experimental data are not available. The experimental chloride binding isotherms were deduced by the free and total chloride profile measurements [11].

By comparing the TE model results with experimental data, the numerical chloride binding isotherms are always overestimated regardless of the mixture (see Figs. 5a, 8a, 11a and 14a). This overestimation is due to the formation of Kuzel's salt. The characteristic threshold effect of the TE is very clear (see Figs. 6a, 9a, 12a and 15a). The precipitation of Kuzel's salt occurs suddenly which yields short fronts. Monosulfoaluminate dissolves quickly and Kuzel's salt and ettringite can precipitate. This process is only controlled by the solubility of the minerals and the diffusion of ions. Therefore, after increasing only a few moles of chloride concentration the amount of monosulfoaluminate is exhausted.

The behavior is very different when the mineral dissolution/precipitation under kinetic control is considered. The differences are very marked (see Figs. 5b, 8b, 11b and 14b). Furthermore, the numerical results with the TK approach are consistent with the experimental 
a) $\mathbf{T E}$

b) TK

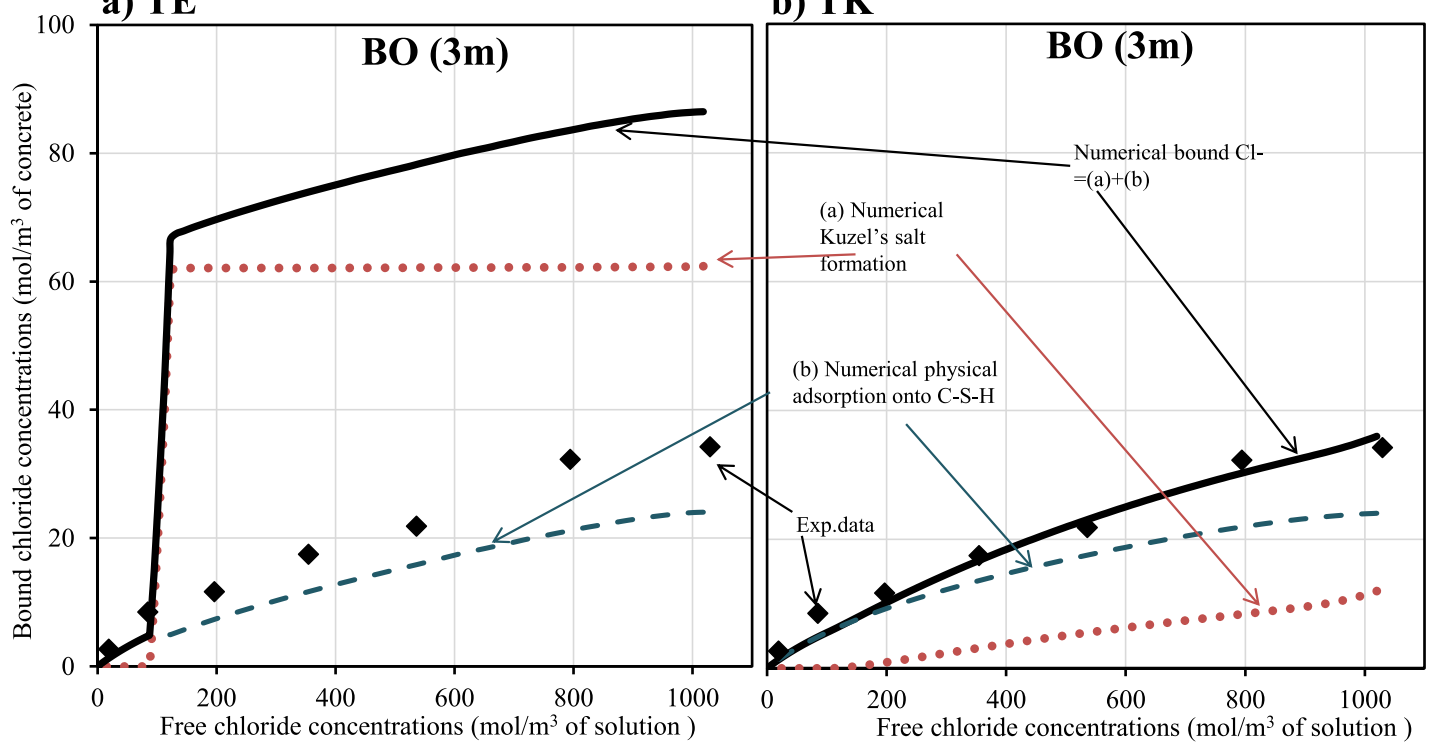

Fig. 5. Chloride binding isotherm for $\mathrm{BO}$ after 3-month exposure to a $60 \mathrm{~g} \cdot \mathrm{L}^{-1} \mathrm{NaCl}$ solution $\left(+4 \mathrm{~g} \cdot \mathrm{L}^{-1} \mathrm{NaOH}\right)$ at $20^{\circ} \mathrm{C}$ [11]. Comparison to numerical simulations: a) TE and b) TK approaches.

a) $\mathrm{TE}$

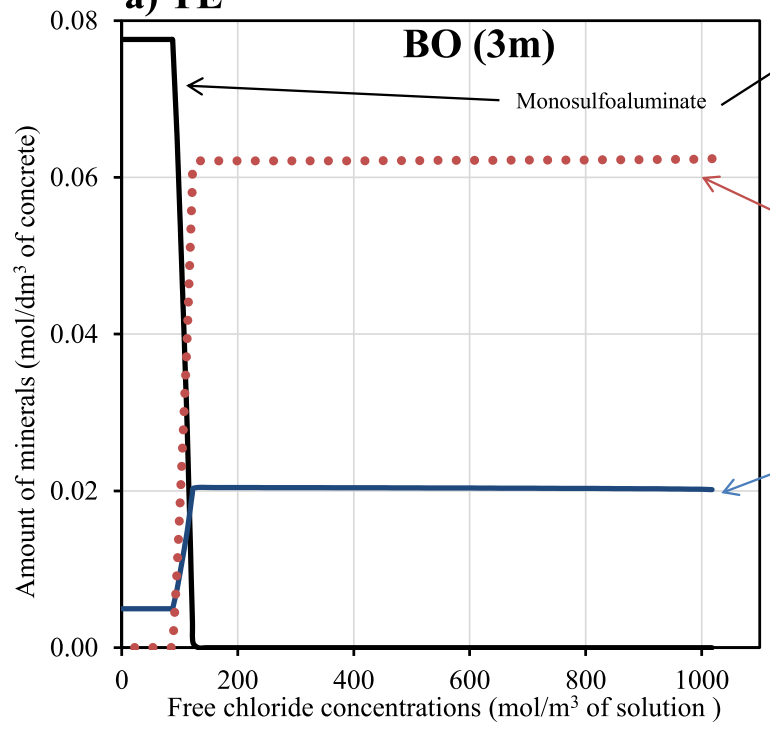

b) TK

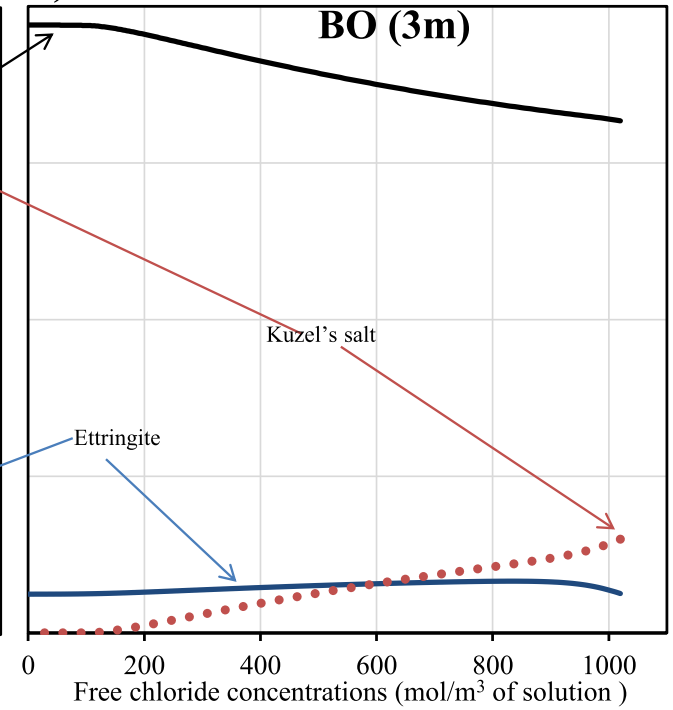

Fig. 6. Solid phases after 3-month exposure to a $60 \mathrm{~g} \cdot \mathrm{L}^{-1} \mathrm{NaCl}$ solution $\left(+4 \mathrm{~g} \cdot \mathrm{L}^{-1} \mathrm{NaOH}\right)$ at $20{ }^{\circ} \mathrm{C}$ : a) TE and b) TK approaches.

results. Figs. $5 \mathrm{~b}, 8 \mathrm{~b}, 11 \mathrm{~b}$ and $14 \mathrm{~b}$ show that monosulfoaluminate is slightly dissolved and is even not exhausted when chloride concentration has reached its maximum value after 3.5- and 7-month exposure for BO, M30FA, M25 and LR-CEM III, respectively. Conversely to the TE approach, the amounts of ettringite and Kuzel's salt are significantly reduced compared to a pure TE model and the effect of the kinetics is underlined.

Figs. 7, 10 and 13 show the total and free chloride concentration profiles for the two approaches. As expected, the overestimation of chloride binding isotherm in the TE has a direct effect on the profiles.
Free chloride concentration is depended not only on the diffusion of chloride ions but also on the equilibrium between the pore solution and the solid species so that the instantaneous reaction in the TE model restrains ingress of chloride ions but promotes chloride binding. The free chloride concentration is therefore always underestimated in the TE for all concretes. For BO, the overestimation of chloride binding isotherm leads to numerical results for total chloride concentration that are close to experimental data (see Fig. 7a). Nevertheless, this closeness is no longer observed for other concretes such as M25 or M30FA (see Figs. 10a and 13a). 


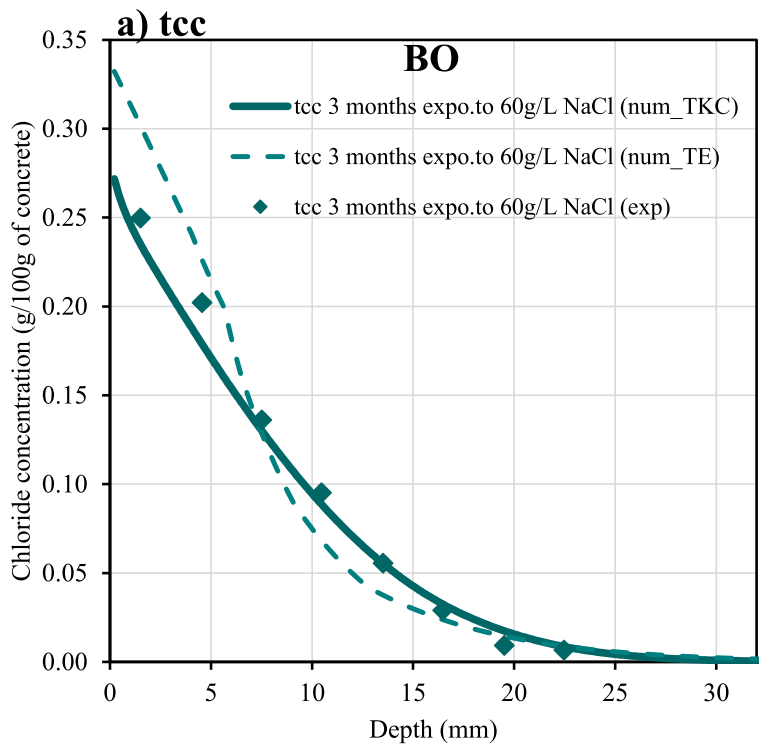

b) $\mathrm{cCl}^{-}$

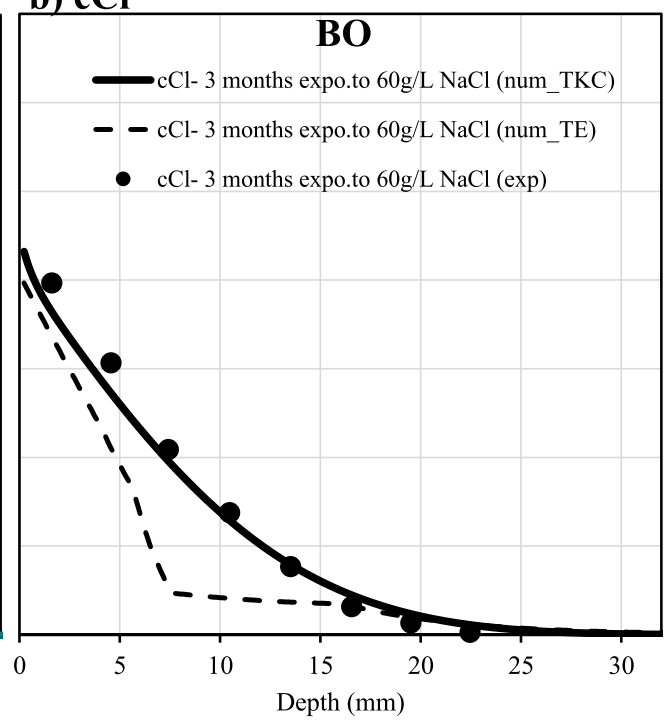

Fig. 7. Chloride concentration profiles obtained by the TE and the TK models for BO after 3-month exposure to a $60 \mathrm{~g} \cdot \mathrm{L}^{-1} \mathrm{NaCl}$ solution $\left(+4 \mathrm{~g} \cdot \mathrm{L}^{-1} \mathrm{NaOH}\right)$ at $20^{\circ} \mathrm{C}$ from the literature [11]. Comparison to numerical simulations: a) Total chloride concentration tcc and b) Free chloride concentration $c_{C^{-}}$.

a) $\mathrm{TE}$

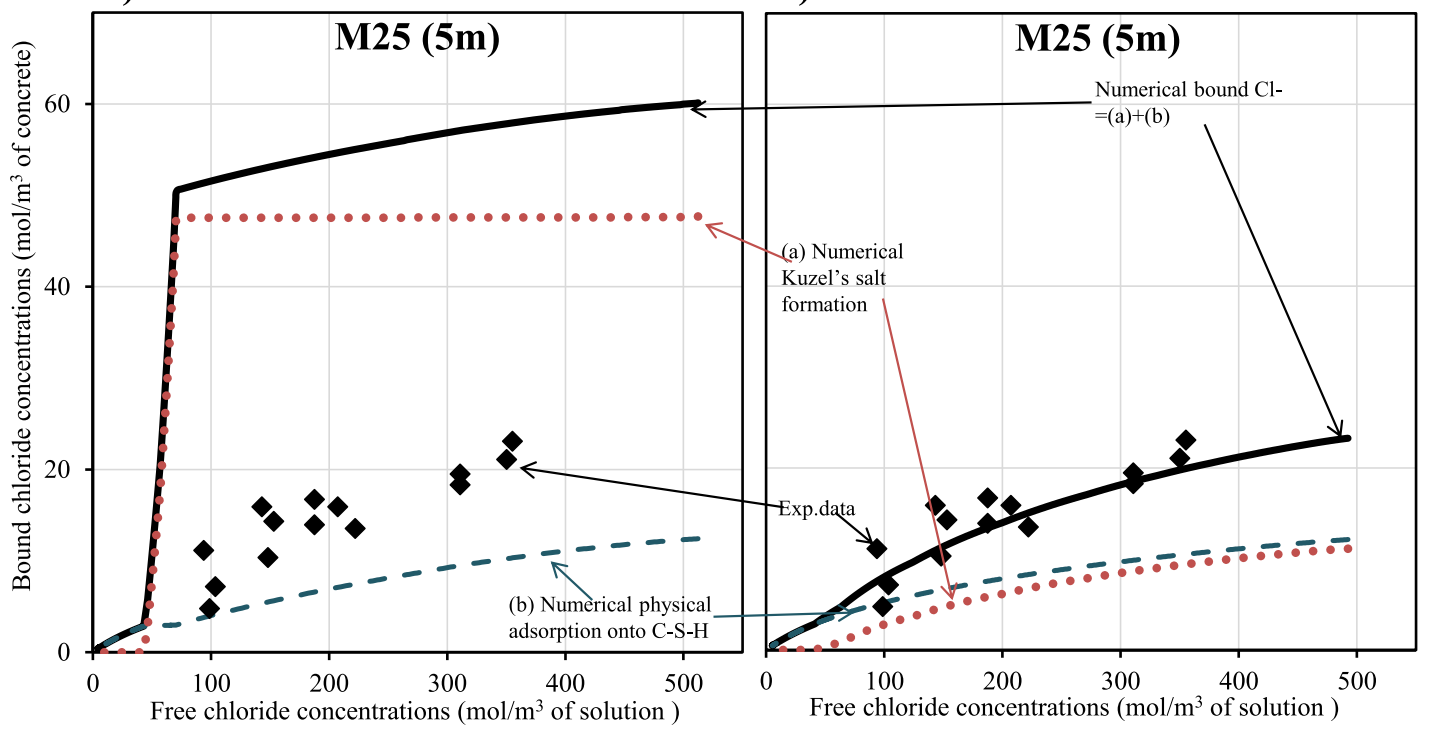

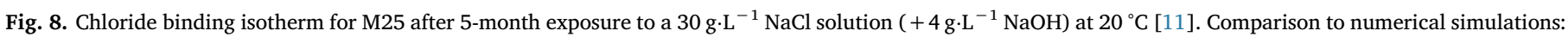
a) TE and b) TK approaches.

The TK approach correctly predicts total and free chloride concentration profiles. The equilibrium between pore solution and solid phases is partially regulated by kinetics. Using kinetics for monosulfoaluminate and ettringite, the TK approach predicts more accurately the total and free chloride concentration profiles than the TE model. That finding is consistent with the Mesbah et al. observations [60] who pointed out that the chemical reactions of a system with Kuzel's salt, monosulfoaluminate and ettringite were far from thermodynamic equilibrium.

\section{Discussion}

\subsection{Number of parameters required for the model}

Section 4.1.1 has shown the relative independence of the chloride binding isotherm with regard to the effective chloride diffusion coefficient, the porosity accessible to water and the apparent density at a given time. This implies that even if no measurement is available for these parameters, The model could be considered as a tool to assess the chloride binding isotherm regardless to the $\mathrm{NaCl}$ exposure solution. 


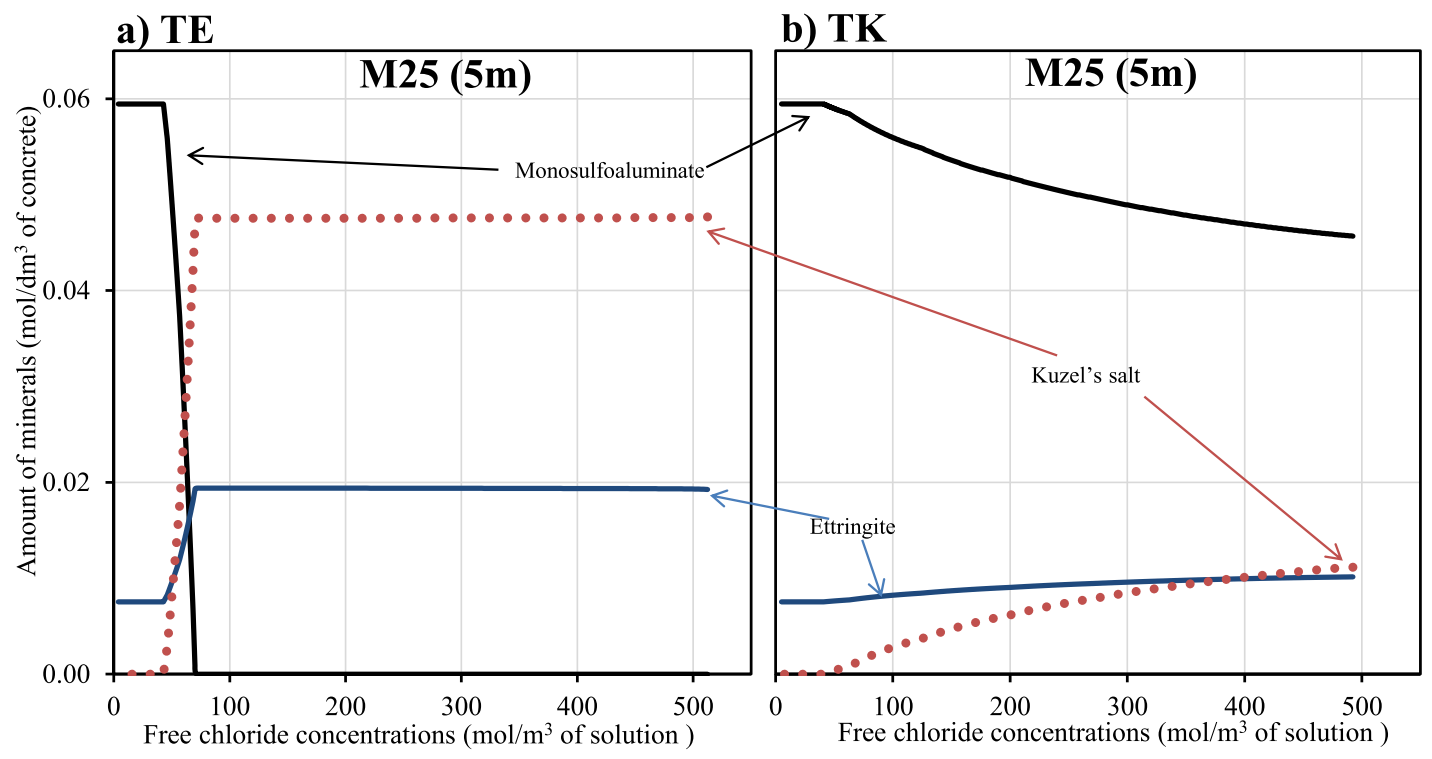

Fig. 9. Solid phases after 5 -month exposure to a $30 \mathrm{~g} \cdot \mathrm{L}^{-1} \mathrm{NaCl}$ solution $\left(+4 \mathrm{~g} \cdot \mathrm{L}^{-1} \mathrm{NaOH}\right)$ at $20^{\circ} \mathrm{C}$ : a) $\mathrm{TE}$ and b) TK approaches.
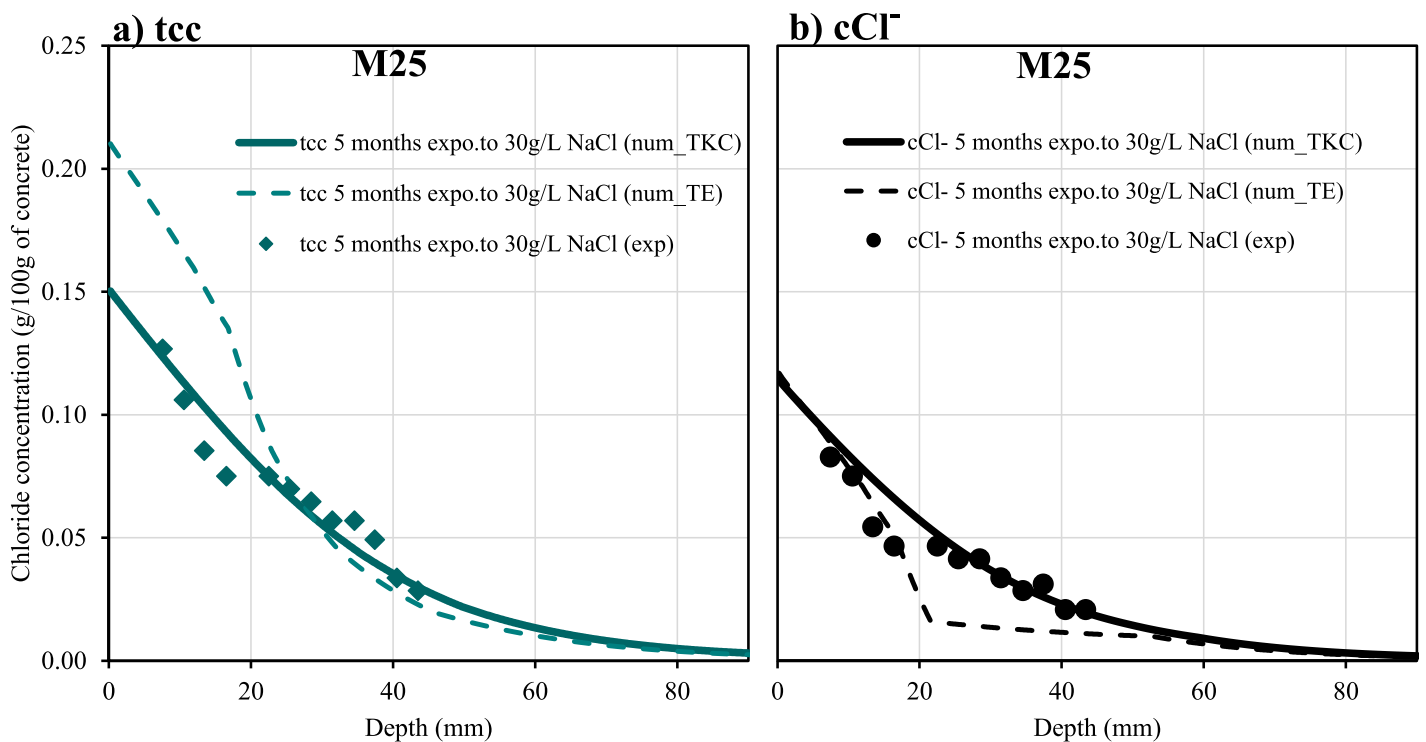

Fig. 10. Chloride concentration profiles obtained by the TE and the TK models for $\mathrm{M} 25$ after 3-month exposure to a $30 \mathrm{~g} \cdot \mathrm{L}^{-1} \mathrm{NaCl}$ solution $\left(+4 \mathrm{~g} \cdot \mathrm{L}^{-1} \mathrm{NaOH}\right)$ at $20^{\circ} \mathrm{C}$ from the literature [11]. Comparison to numerical simulations: a) total chloride concentration $t c c$ and b) free chloride concentration $c_{\mathrm{Cl}^{-}}$.

On the other hand the results given in Fig. 16 show a significant dependence of the total chloride concentration profiles to the effective diffusion coefficient. This latter coefficient is an important parameter in all numerical models because diffusion is the principal transport phenomenon.

Hence, the parameters required for the model are the cement composition and the concrete mix-design. Mean values for the effective chloride diffusion coefficient, the porosity accessible to water and the apparent density that can be found in the literature are sufficient to simulate chloride binding isotherm. More precise values are necessary in order to simulate chloride profiles. The model does not need any value if an initial profile is available as explained in Baroghel-Bouny et al.'s work [72] (except if the diffusion coefficient evolution is a function of time).

\subsection{Analysis of chloride binding evolution with time}

Fig. 17 shows that the chloride binding isotherm changes with time. The amount of bound chloride ions is greater after 5-month exposure than after 3-month exposure. This is due to a growth up of the chloride bound by Kuzel's salt formation with time. On the other hand, the "physical" chloride binding onto C-S-H is the same after 3 and 5 months of exposure.

Chloride binding by Kuzel's salt formation slightly growths up 


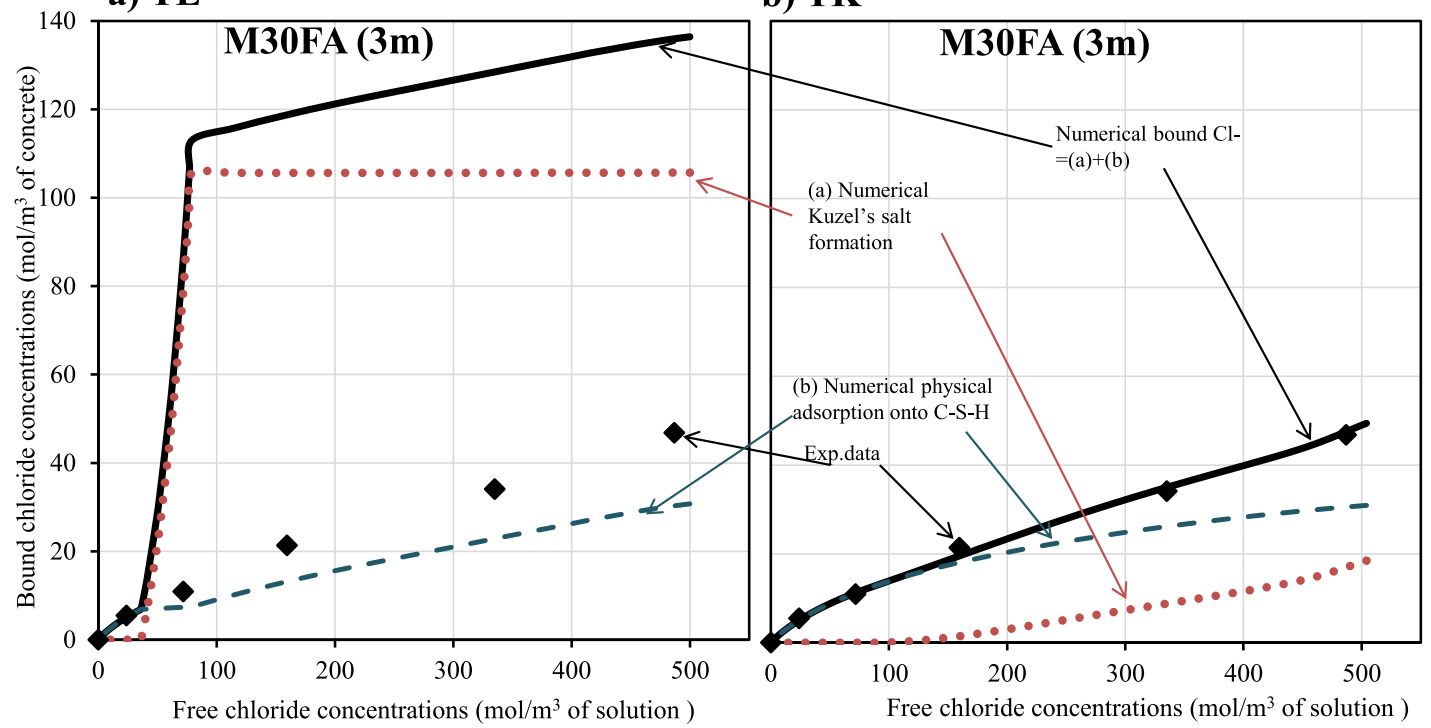

Fig. 11. Chloride binding isotherm for M30FA after 3 months exposure to a $30 \mathrm{~g} \cdot \mathrm{L}^{-1} \mathrm{NaCl}$ solution $\left(+4 \mathrm{~g} \cdot \mathrm{L}^{-1} \mathrm{NaOH}\right)$ at $20^{\circ} \mathrm{C}[11]$. Comparison to numerical simulations: a) TE and b) TKC approaches.

a) $\mathbf{T E}$

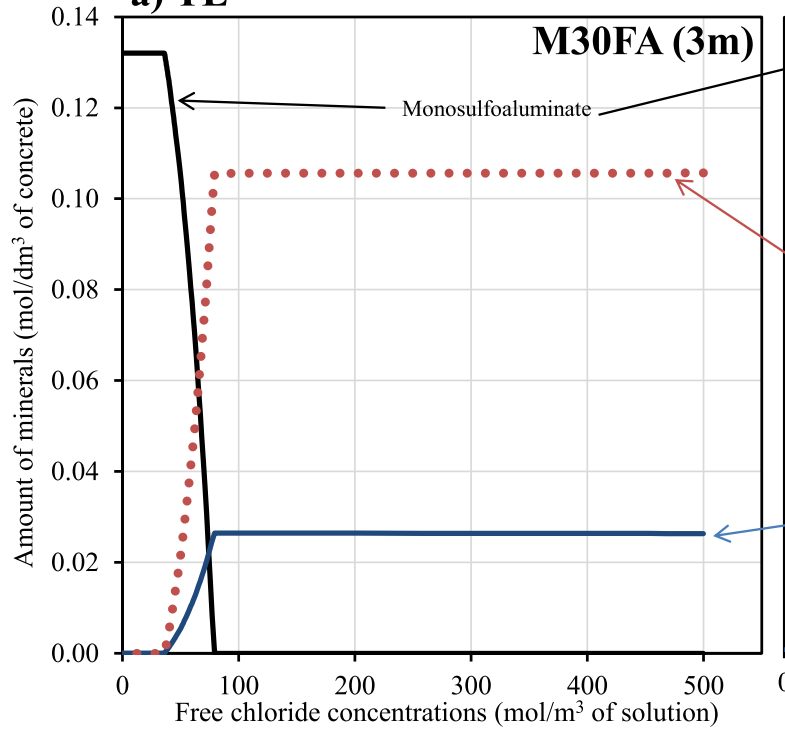

b) TK

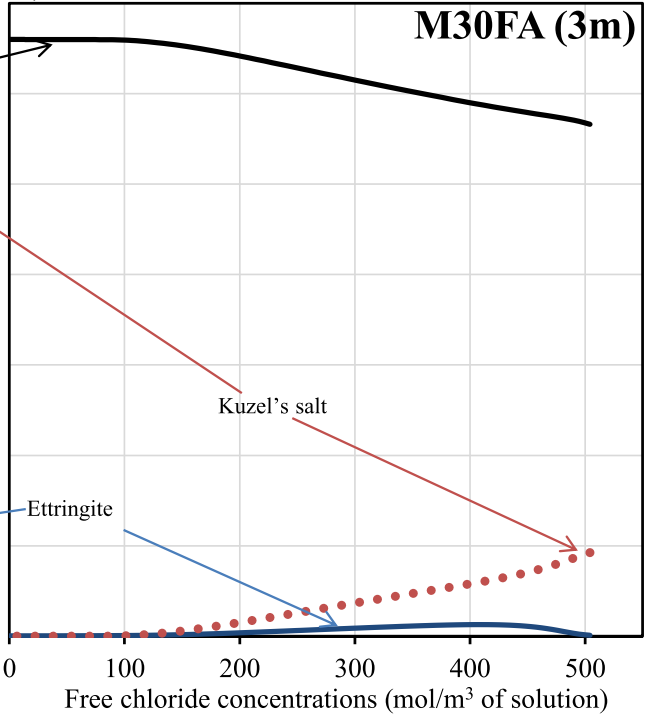

Fig. 12. Solid phases after 3-month exposure to a $30 \mathrm{~g} \cdot \mathrm{L}^{-1} \mathrm{NaCl}$ solution $\left(+4 \mathrm{~g} \cdot \mathrm{L}^{-1} \mathrm{NaOH}\right)$ at $20^{\circ} \mathrm{C}$ : a) $\mathrm{TE}$ and b) $\mathrm{TK}$ approaches.

owing to kinetic effects (see Fig. 17a). After 5 months of exposure, chloride binding by Kuzel's salt formation is equivalent to the "physical" chloride binding. At equilibrium state, the results in TE show a significant amount of bound chlorides by Kuzel's formation (see also Section 4.2). The prominence of "physical" chloride binding or chloride binding by Kuzel's formation greatly depends on time and on the mixture.

The amount of chloride ions bound onto C-S-H obtained by the present model are very close to those obtained by Henocq et al. [73]. By comparing Fig. 2 in the paper of Henocq et al. and Fig. 7 in the present study, this amount is in the same range of magnitude. Henocq et al. found values between 0.015 and $0.022 \mathrm{~mol} / \mathrm{mol}$ of $\mathrm{Si}$. In the present study model gives about $15 \mathrm{~mol} / \mathrm{m}^{3}$ of concrete that is to say about $0.018 \mathrm{~mol} / \mathrm{mol}$ of Si (Table 5 gives $0.8 \mathrm{~mol} / \mathrm{dm}^{3}$ of concrete for Jennite and Tobermorite for M25).

\subsection{Limits of the model}

Today, the model has been used on a limited number of cases: several concretes exposed to $\mathrm{NaCl}$ solutions with a high $\mathrm{pH}$ value. It cannot be generalized to other boundary solutions with other cations associated with chloride ions or with lower $\mathrm{pH}$ value. 

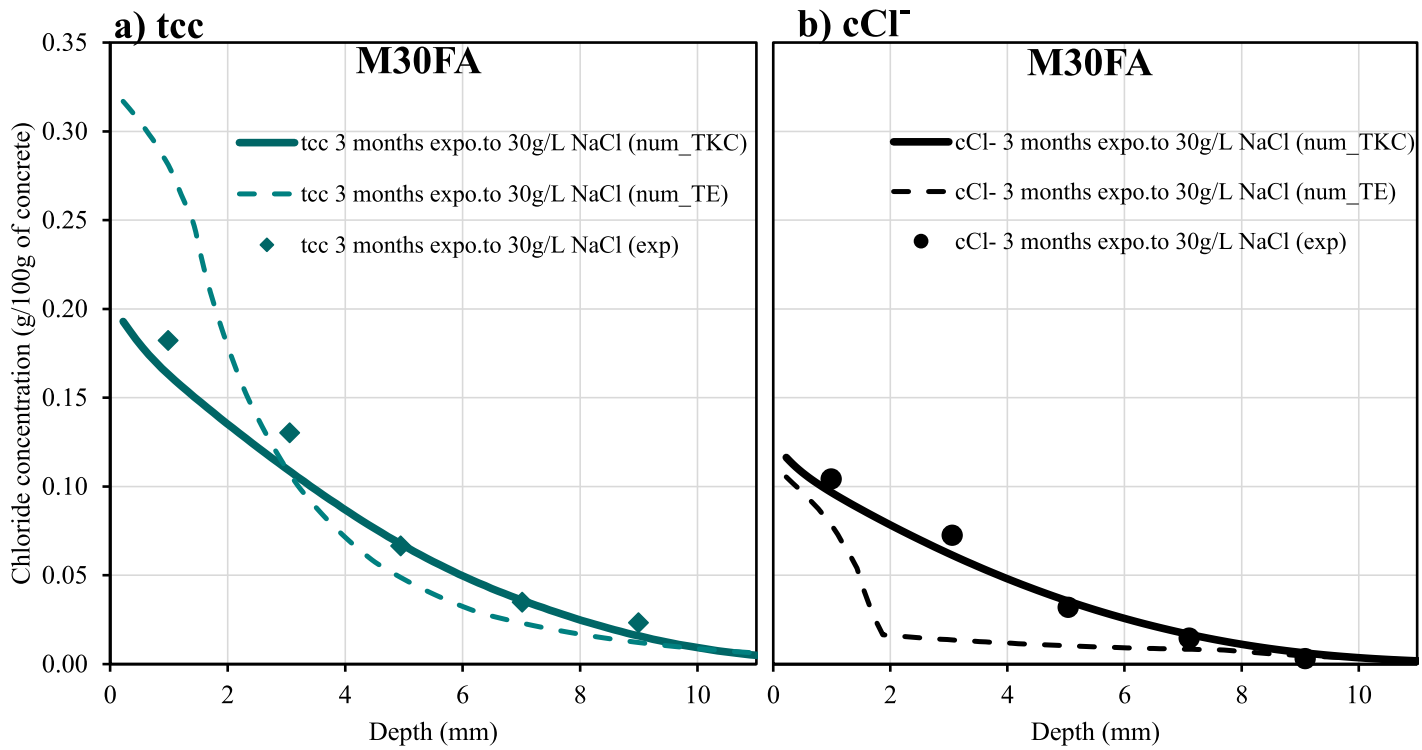

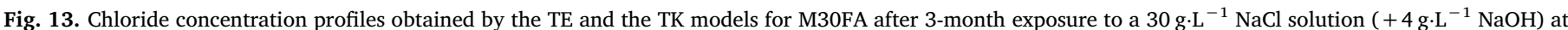
$20{ }^{\circ} \mathrm{C}$ from the literature [11]. Comparison to numerical simulations: a) total chloride concentration $t c c$ and b) free chloride concentration $c_{C l^{-}}$.

a) $\mathrm{TE}$

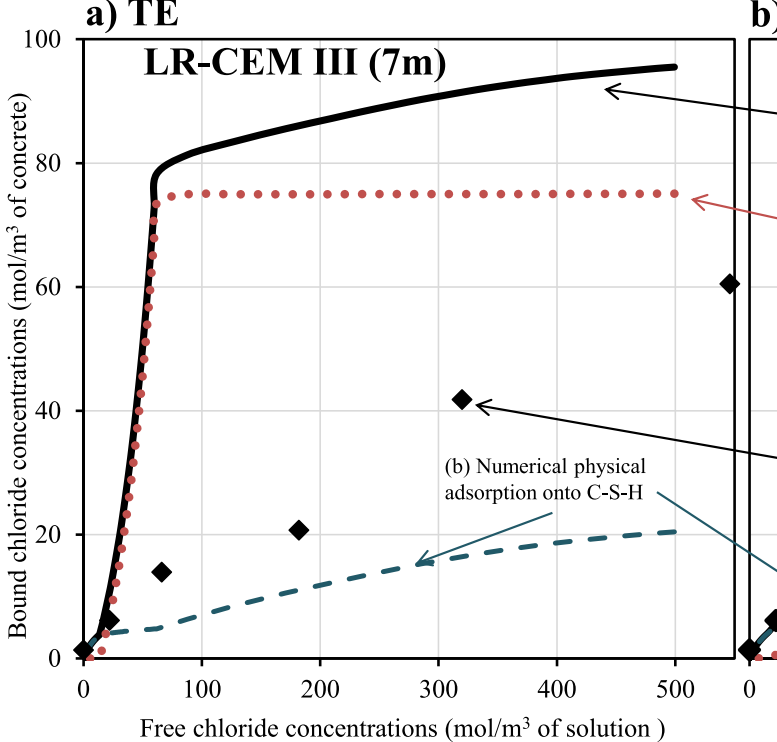

b) TK

\section{LR-CEM III (7m)}

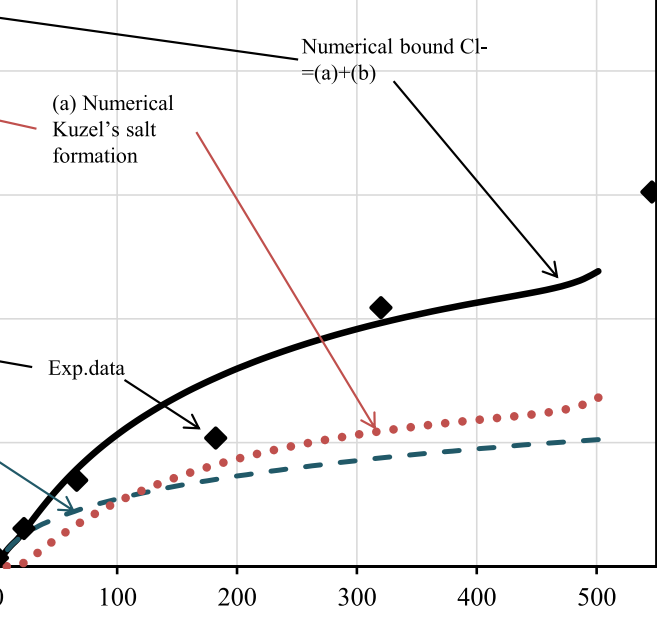

Free chloride concentrations $\left(\mathrm{mol} / \mathrm{m}^{3}\right.$ of solution )

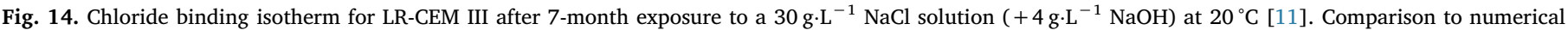
simulations: a) TE and b) TK approaches.

In the literature, Kalinichevet et al. [38] showed that out of C-S-H, physical adsorption of ions onto ettringite, chloride AFm (Kuzel's salt, Friedel's salt), portlandite may also take place in hydrated cement paste. Elakneswaran et al. [39] concluded that physical adsorption of chlorides in the hydrated cement paste is dominated by C-S-H. Moreover, the specific surface site of portlandite and chloride-AFm measured were $14.31 \mathrm{~m}^{2} \cdot \mathrm{g}^{-1}$ and $48.43 \mathrm{~m}^{2} \cdot \mathrm{g}^{-1}$ [39] respectively, which are lower than the chosen specific surface site value used for C-S-H $500 \mathrm{~m}^{2}$ . $\mathrm{g}^{-1}$ in the surface complexation model. In addition, the amount of ettringite is low in the concretes studied (see Table 5). The consideration of the surface complexation model onto only C-S-H was consequently reasonable in this investigation but detrimental in other situations.

$\mathrm{NaCl}$ exposure conditions were used to validate the model. Nevertheless, number of authors [75-77] have noticed that the cations associated with chloride ions influence the diffusion behavior of chloride ions and their binding capacity in concrete. These authors showed that the chloride binding capacities decrease in the order $\mathrm{Ca}^{2+}>\mathrm{Mg}^{2+}>\mathrm{Na}^{+}$. Elakneswaran et al. [12] proposed that chloride ions adsorption is favored onto C-S-H surface where initially $\mathrm{Ca}^{2+}$ is adsorbed according to the reaction: 
a) TE

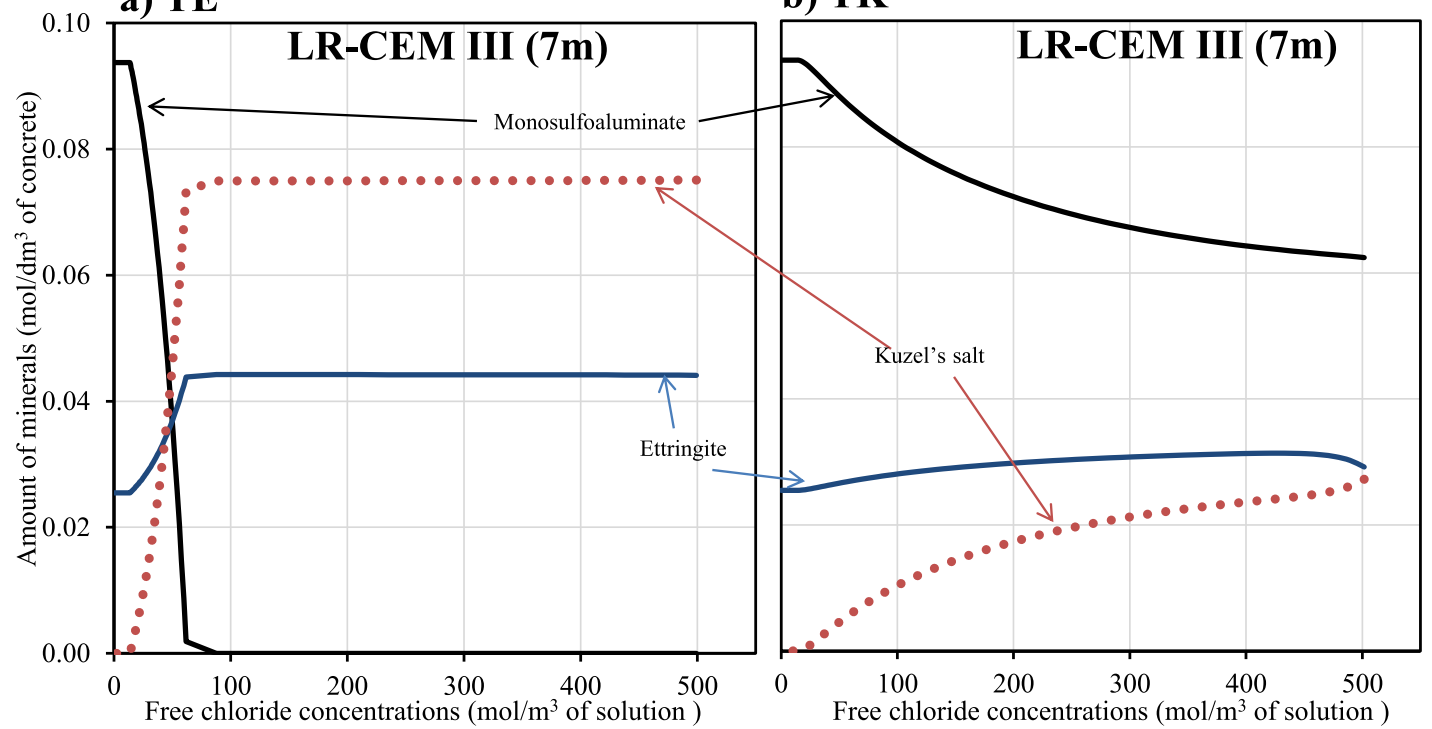

Fig. 15. Solid phases during after 7-month exposure to a $30 \mathrm{~g} \cdot \mathrm{L}^{-1} \mathrm{NaCl}$ solution $\left(+4 \mathrm{~g} \cdot \mathrm{L}^{-1} \mathrm{NaOH}\right)$ at $20^{\circ} \mathrm{C}$ : a) $\mathrm{TE}$ and b) TK approaches.

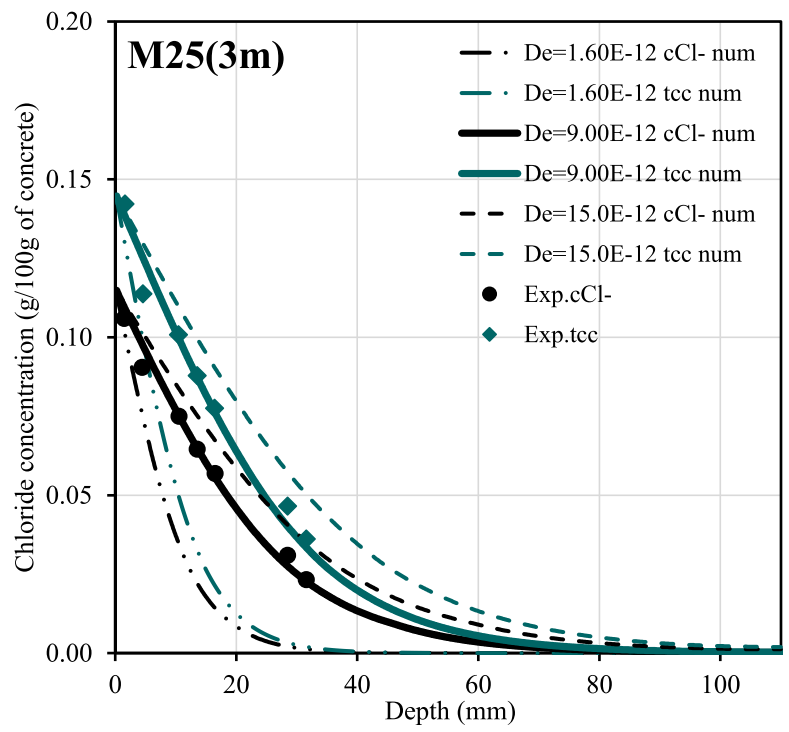

Fig. 16. Total chloride concentration tcc profiles and free chloride concentration profile $c_{\mathrm{Cl}^{-}}$for M25 after 3-month exposure to a $30 \mathrm{~g} \cdot \mathrm{L}^{-1} \mathrm{NaCl}$ solution $\left(+4 \mathrm{~g} \cdot \mathrm{L}^{-1} \mathrm{NaOH}\right)$ at $20{ }^{\circ} \mathrm{C}$ from the literature [11].

$\equiv \mathrm{SiOH}+\mathrm{Ca}^{2+}+\mathrm{Cl}^{-} \leftrightarrow \equiv \mathrm{SiOCaCl}+\mathrm{H}^{+}$

In this paper, all concretes are exposed to $\mathrm{NaCl}$ solutions. Therefore, the adsorption of complex $\mathrm{CaCl}^{+}$onto C-S-H surface would not influence the results of the model. Moreover, the constant rate $k$ of monosulfoaluminate, ettringite and C-S-H from [61] were determined in high $\mathrm{pH}$ conditions as in the present study $(\mathrm{pH}=12.95)$. Regarding the surface complexation model, the numbers of sorption reactions given in Table 1 and the sorption density value $\Gamma_{C-S-H}=1.3 \times 10^{-6} \mathrm{~mol} \cdot \mathrm{m}^{-2}$ obtained in this paper are used only for exposure to $\mathrm{NaCl}$ solution.

More research on surface complexation models needs to be carried out when the cementitious material is exposed to $\mathrm{CaCl}_{2}, \mathrm{MgCl}_{2}$ solution or in seawater where many ions are present (sulfate, carbonate). In low $\mathrm{pH}$ seawater, the parameters of kinetic control need to be verified.

Finally, no distinction is made between free water and water bound in the electric doubles layers. However, although diffusion is not stopped in bound water it may be slowed down. This effect may happen for HPC concretes for which the model has to be validated.

\section{Conclusion}

In this paper a coupled thermodynamic equilibrium/kinetic and surface complexation model was proposed in order to simulate chloride binding isotherm and total and free chloride profiles. Sensitivity analysis of sorption density in a surface complexation model was firstly carried out to determine the sorption density value of C-S-H which is not available in the literature to the authors' knowledge. Experimental results for various concretes, with different water/binder ratios and various types of binder (CEM I, CEM I with fly ash and CEM III), exposed to various $\mathrm{NaCl}$ solution concentrations are compared to numerical results.

A value of $\Gamma_{C-S-H}=1.3 \times 10^{-6} \mathrm{~mol} \cdot \mathrm{m}^{-2}$ is obtained by comparing experimental and numerical results.

Using only the mix-design of concrete, the chemical composition of the binder and effective diffusion coefficient and porosity accessible to water values taken from the literature as input data, the proposed model gives a value of $\Gamma_{C-S-H}=1.3 \times 10^{-6} \mathrm{~mol} \cdot \mathrm{m}^{-2}$ for the sorption density of C-S-H. In addition, a good correlation between experimental data and numerical results are obtained on chloride binding isotherm. The model can detail "physical" chloride binding and chloride binding by Kuzel's salt formation.

Furthermore, the numerical results show that incorporating thermodynamic/kinetics is essential in order to retrieve experimental evolution of chloride binding isotherm as a function of time. In particular, the slightly decrease of the amount of Monosulfoaluminate permit to retrieve the slightly growth up of the binding chloride ions that is observed experimentally. This model may be useful for concretes exposed 
a) 3 months (M25-TK)

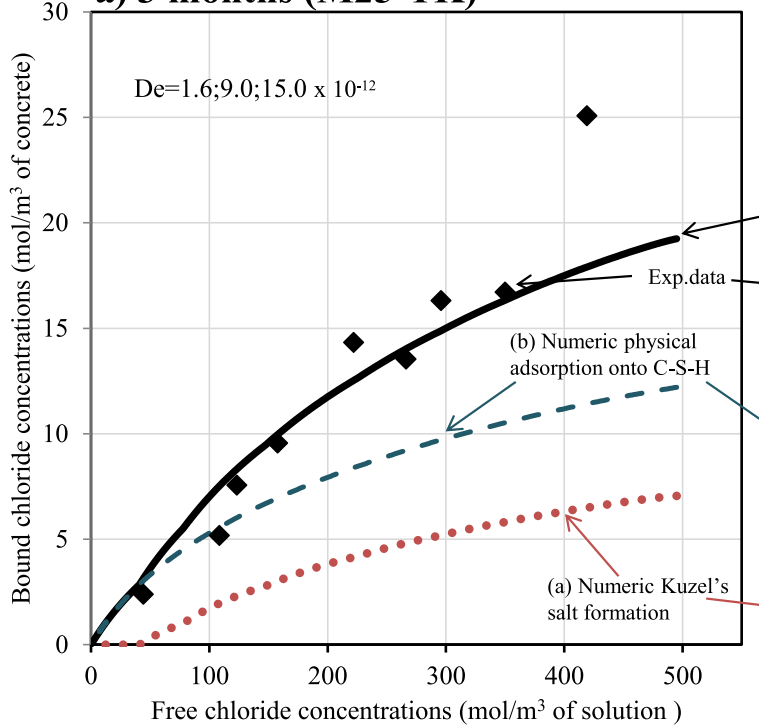

b) 5 months (M25-TK)

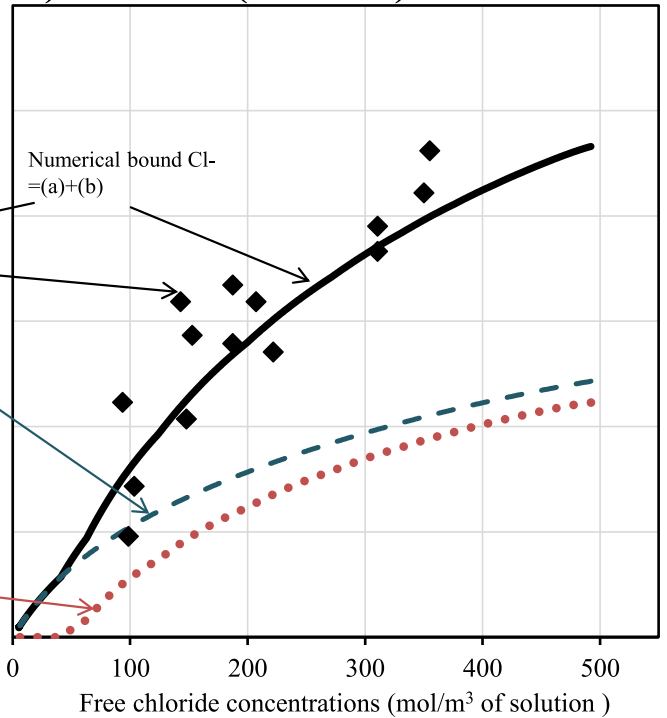

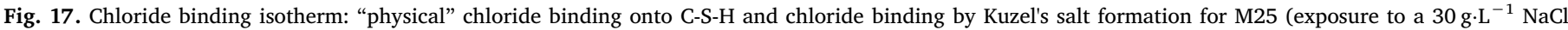
solution $\left(+4 \mathrm{~g} \cdot \mathrm{L}^{-1} \mathrm{NaOH}\right)$ at $\left.20^{\circ} \mathrm{C}[11]\right)$. Comparison with numerical simulations: a) after 3-month and b) after 5-month exposure.

to a $\mathrm{NaCl}$ solution with high $\mathrm{pH}$. The model needs to be improved in order to simulate the ingress of ions in concretes exposed to seawater or $\mathrm{CaCl}_{2}, \mathrm{MgCl}_{2}$ solutions.

\section{Acknowledgments}

This work offers a contribution to the French ANR MODEVIE project. The authors are grateful to the "Agence National de la Recherche" and the french ministries in charge of sustainable development, town planning and transportation for their financial support in favor of the project.

\section{References}

[1] American Society for Testing and Material, ASTM C-1152. Standard test method for acid-soluble chloride in mortar and concrete, (2012).

[2] C. Alonso, C. Andrade, M. Castellote, P. Castro, Chloride threshold values to depassivate reinforcing bars embedded in a standardized $\{\mathrm{OPC}\}$ mortar, Cem. Concr. Res. 30 (7) (2000) 1047-1055.

[3] D. Hausmann, Steel corrosion in concrete. how does it occur? Mater. Prot. 6 (1967) 19-23.

[4] V. Gouda, Corrosion and corrosion inhibition of reinforcing steel. i. Immersed in alkaline solutions, Br. Corros. J. 5 (1970) 198-203.

[5] L. Li, A.A. Sagüés, Chloride corrosion threshold of reinforcing steel in alkaline solutions-open-circuit immersion tests, Corrosion 57 (1) (2001) 19-28.

[6] E. Samson, J. Marchand, K. Snyder, J. Beaudoin, Modeling ion and fluid transport in unsaturated cement systems in isothermal conditions, Cem. Concr. Res. 35 (1) (2005) 141-153.

[7] V. Baroghel-Bouny, M. Thiéry, X. Wang, Modelling of isothermal coupled moisture-ion transport in cementitious materials, Cem. Concr. Res. 41 (8) (2011) 828-841.

[8] P. Nguyen, O. Amiri, Study of electrical double layer effect on chloride transport in unsaturated concrete, Constr. Build. Mater. 50 (2014) 492-498.

[9] E. Samson, J. Marchand, Modeling the effect of temperature on ionic transport in cementitious materials, Cem. Concr. Res. 37 (2007) 455-468.

[10] S.-H. Han, Influence of diffusion coefficient on chloride ion penetration of concrete structure, Constr. Build. Mater. 21 (2) (2007) 370-378.

[11] V. Baroghel-Bouny, X. Wang, M. Thiery, M. Saillio, F. Barberon, Prediction of chloride binding isotherms of cementitious materials by analytical model or numerical inverse analysis, Cem. Concr. Res. 42 (9) (2012) 1207-1224.

[12] Y. Elakneswaran, A. Iwasa, T. Nawa, T. Sato, K. Kurumisawa, Ion-cement hydrate interactions govern multi-ionic transport model for cementitious materials, Cem. Concr. Res. 40 (12) (2010) 1756-1765.

[13] E. Samson, J. Marchand, Modeling the transport of ions in unsaturated cementbased materials, Comput. Struct. 85 (23 - 24) (2007) 1740-1756.
[14] Y. Maltais, E. Samson, J. Marchand, Predicting the durability of portland cement systems in aggressive environments-laboratory validation, Cem. Concr. Res. 34 (9) (2004) 1579-1589.

[15] B. Lothenbach, B. Bary, P.L. Bescop, T. Schmidt, N. Leterrier, Sulfate ingress in portland cement, Cem. Concr. Res. 40 (8) (2010) 1211-1225.

[16] Y. Hosokawa, K. Yamada, B. Johannesson, L.-O. Nilsson, Development of a multispecies mass transport model for concrete with account to thermodynamic phase equilibriums, Mater. Struct. 44 (9) (2011) 1577-1592.

[17] B. Bary, N. Leterrier, E. Deville, P.L. Bescop, Coupled chemo-transport-mechanical modelling and numerical simulation of external sulfate attack in mortar, Cem. Concr. Compos. 49 (2014) 70-83.

[18] M. Jensen, K.D. Weerdt, B. Johannesson, M. Geiker, Use of a multi-species reactive transport model to simulate chloride ingress in mortar exposed to $\mathrm{NaCl}$ solution or sea-water, Comput. Mater. Sci. 105 (2015) 75-82.

[19] A. Soive, E. Roziere, A. Loukili, Parametrical study of the cementitious materials degradation under external sulfate attack through numerical modeling, Constr. Build. Mater. 112 (2016) 267-275.

[20] B. Lothenbach, Thermodynamic equilibrium calculations in cementitious systems, Mater. Struct. 43 (2010) 1413-1433.

[21] N.C. Marty, C. Tournassat, A. Burnol, E. Giffaut, E.C. Gaucher, Influence of reaction kinetics and mesh refinement on the numerical modelling of concrete/clay interactions, J. Hydrol. 364 (1-2) (2009) 58-72.

[22] N.C.M. Marty, O. Bildstein, P. Blanc, F. Claret, B. Cochepin, E.C. Gaucher, D. Jacques, J.-E. Lartigue, S. Liu, K.U. Mayer, J.C.L. Meeussen, I. Munier, I. Pointeau, D. Su, C.I. Steefel, Benchmarks for multicomponent reactive transport across a cement/clay interface, Comput. Geosci. 19 (3) (2015) 635-653.

[23] T.J. Tambach, M. Koenen, L.J. Wasch, F. van Bergen, Geochemical evaluation of $\left\{\mathrm{CO}_{2}\right\}$ injection and containment in a depleted gas field, Int. J. Greenhouse Gas Control 32 (2015) 61-80.

[24] B. Johannesson, Comparison between the Gauss' law method and the zero current method to calculate multi-species ionic diffusion in saturated uncharged porous materials, Comput. Geotech. 37 (2010) 667-677.

[25] T. Nagel, H. Shao, A.K. Singh, N. Watanabe, C. Roßkopf, M. Linder, A. Worner, O. Kolditz, Non-equilibrium thermochemical heat storage in porous media: part 1 conceptual model, Energy 60 (2013) 254-270.

[26] J. van der Lee, L. De Windt, V. Lagneau, P. Goblet, Moduleoriented modeling of reactive transport with HYTEC, Comput. Geosci. 29 (2003) 265-275.

[27] T. Xu, N. Spycher, E. Sonnenthal, TOUGHREACT User's Guide: A Simulation Program for Non-isothermal Multiphase Reactive Transport in Variably Saturated Geologic Media, version 2.0, Tech. Rep. Lawrence Berkeley National Laboratory, 2012october.

[28] M.D. White, M. Oostrom, STOMP Subsurface Transport Over Multiple Phases Version 4.0 User's Guide, Pacific Northwest National Laboratory, Washington, 2006.

[29] G.T. Yeh, C.H. Tsai, HYDROGEOCHEM 6.0: A Two Dimensional Model of Coupled Fluid Flow, Thermal Transport, Geomechanics, and HYDROGEOCHEMical Transport Through Multiple Phase Systems Version 6.0 (FACTM2D: A Model for Multi-phase Flow Analysis and Reactive Chemical Transport, Thermal Transport, and Mechanics Simulation, 2-dimensional Version) - Theoretical Basis and 
Numerical Approximation, Graduate Institute of Applied Geology, National Central University, Jhongli, 2013.

[30] P.C. Lichtner, G.E. Hammond, C. Lu, S. Karra, G. Bisht, B. Andre, R.T. Mills, J. Kumar, PFLOTRAN User Manual: A Massively Parallel Reactive Flow and Transport Model for Describing Surface and Subsurface Processes, (2013).

[31] C.I. Steefel, C.A.J. Appelo, B. Arora, D. Jacques, T. Kalbacher, O. Kolditz, V. Lagneau, P.C. Lichtner, K.U. Mayer, J.C.L. Meeussen, S. Molins, D. Moulton, H. Shao, J. Simunek, N. Spycher, S.B. Yabusaki, G.T. Yeh, Reactive transport codes for subsurface environmental simulation, Comput. Geosci. 19 (2015) 445-478.

[34] J. Beaudoin, V. Ramachandran, R. Feldman, Interaction of chloride and csh, Cem. Concr. Res. 20 (6) (1990) 875-883.

[35] H. Viallis-Terrisse, A. Nonat, J. Petit, Zeta-potential study of calcium silicate hydrates interacting with alkaline cations, J. Colloid Interface Sci. 244 (2001) 58-65.

[36] P. Henocq, Moélisation des interactions ioniques a la surface des silicates de calcium hydratés, Université Laval-Quebec et Université de Cergy-Pontoise, 2005 Ph.D. thesis.

[37] D.A. Dzombak, F.M. Morel, Surface complexation modelling: hydrous ferric oxide, A Wiley-Interscience Publication, 1990.

[38] A.G. Kalinichev, R.J. Kirkpatrick, Molecular dynamics modeling of chloride binding to the surfaces of calcium hydroxide, hydrated calcium aluminate, and calcium silicate phases, Chem. Mater. 14 (8) (2002) 3539-3549.

[39] Y. Elakneswaran, T. Nawa, K. Kurumisawa, Electrokinetic potential of hydrated cement in relation to adsorption of chlorides, Cem. Concr. Res. 39 (4) (2009) 340-344.

[40] B. Lothenbach, T. Matschei, G. Möschner, F.P. Glasser, Thermodynamic modelling of the effect of temperature on the hydration and porosity of portland cement, Cem. Concr. Res. 38 (1) (2008) 1-18.

[41] D.A. Kulik, M. Kersten, Aqueous solubility diagrams for cementitious waste stabilization systems: II, end-member stoichiometries of ideal calcium silicate hydrate solid solutions, J. Am. Ceram. Soc. 84 (12) (2001) 3017-3026.

[42] T. Heath, D. Ilett, C. Tweed, Thermodynamic modelling of the sorption of radioelements onto cementitious materials, Mater. Res. Soc. Symp. Proc. 421 (1996) 44-449.

[43] H. Viallis-Terrisse, Interaction des silicates de calcium hydrates-principaux constituants duciment avec les chlorures d'alcalins .analogie avec les argiles, Universite de Bourgogne, 2000 Ph.D. thesis.

[44] P. Debye, E. Huckel, The theory of electrolytes. i. Lowering of freezing point and related phenomena, Phys. Z. 24 (1923) 185-206.

[45] C. Davies, Ion Association, Butterwoths, 1962.

[46] A. Truesdell, B. Jones, Wateq-a computer program for calculating chemical equilibria of natural waters, U.S. Geol. Surv. J. Res. 2 (1974) 233-248.

[47] H.C. Helgeson, D.H. Kirkham, G.C. Flowers, Theoretical Prediction of the Thermodynamic Behavior of Aqueous Electrolytes by High Pressures and Temperatures, IV, Calculation of activity coefficients, osmotic coefficients and apparent molal and standard relative partial molal properties to 600 degree, (1981).

[48] R. Barbarulo, J. Marchand, K. Snyder, S. Prené, Dimensional analysis of ionic transport problems in hydrated cement systems: part 1. Theoretical considerations, Cem. Concr. Res. 30 (12) (2000) 1955-1960.

[49] L. De Windt, F. Marsal, E. Tinseau, D. Pellegrini, Reactive transport modeling of geochemical interactions at a concrete/argillite interface, Tournemire site (France), Phys. Chem. Earth, A/B/C 33 (2008) S295-S305.

[50] L. De Windt, P. Devillers, Modeling the degradation of portland cement pastes by biogenic organic acids, Cem. Concr. Res. 40 (8) (2010) 1165-1174.

[51] P. Lalan, A. Dauzères, L. De Windt, D. Bartier, J. Sammaljärvi, J.-D. Barnichon, I. Techer, V. Detilleux, Impact of a $70^{\circ} \mathrm{C}$ temperature on an ordinary portland cement paste/claystone interface: an in situ experiment, Cem. Concr. Res. 83 (2016) 164-178.

[52] C. Steefel, A. Lasaga, A coupled model for transport of multiple chemical species and kinetic precipitation/dissolution reactions with application to reactive flow in single phase hydrothermal systems, Am. J. Sci. 294 (1994) 529-592.

[53] A.C. Lasaga, J.M. Soler, J. Ganor, T.E. Burch, K.L. Nagy, Chemical weathering rate laws and global geochemical cycles, Geochim. Cosmochim. Acta 58 (10) (1994) 2361-2386.

[54] J.I. Drever, The Geochemistry of Natural Waters, 3rd ed., Prentice Hall, Upper
Saddle River NJ, 1997.

[55] D.A. Kulik, T. Wagner, S.V. Dmytrieva, G. Kosakowski, F.F. Hingerl, K.V. Chudnenko, U.R. Berner, Gem-selektor geochemical modeling package: revised algorithm and GEMS3K numerical kernel for coupled simulation codes, Comput Geosci. 17 (1) (2013) 1-24 http://gems.web.psi.ch.

[56] B. Lothenbach, F. Winnefeld, Thermodynamic modelling of the hydration of portland cement, Cem. Concr. Res. 36 (2006) 209-226.

[57] T. Matschei, B. Lothenbach, F.P. Glasser, Thermodynamic properties of portland cement hydrates in the system CaO-Al2O3-SiO2-CaSO4-CaCO3-H2O, Cem. Concr. Res. 37 (10) (2007) 1379-1410.

[58] T. Thoenen, D. Kulik, Nagra/psi chemical thermodynamic data base 01/01 for the gem-selektor (v.2-psi) geochemical modeling code, release 28-02-03, PSI Technical Report TM-44-03-04, 2003.

[59] S. Yoon, J. Ha, S.R. Chae, D.A. Kilcoyne, Y. Jun, J.E. Oh, P.J. Monteiro, Phase changes of monosulfoaluminate in $\mathrm{NaCl}$ aqueous solution, Materials 9 (5) (2016) 401.

[60] A. Mesbah, C. Cau-dit Coumes, G. Renaudin, F. Frizon, F. Leroux, Uptake of chloride and carbonate ions by calcium monosulfoaluminate hydrate, Cem. Concr. Res. 42 (2012) 1157-1165.

[61] I. Baur, P. Keller, D. Mavrocordatos, B. Wehrli, C. Johnson, Dissolution-precipitation behaviour of ettringite, monosulfate, and calcium silicate hydrate, Cem. Concr. Res. 34 (2004) 341-348.

[62] S. Gali, C. Ayora, P. Alfonso, E. Tauler, M. Labrador, Kinetics of dolomiteportlandite reaction: application to portland cement concrete, Cem. Concr. Res. 31 (6) (2001) 933-939.

[63] J. Palandri, Y. Kharaka, A compilation of rate parameters of water-mineral interaction kinetics for application to geochemical modeling in US geological survey open file report, Tech. rep, USGS, 2004.

[64] H. Taylor, Cement Chemistry, Thomas Telford, 1997.

[65] V. Baroghel-Bouny, P. Belin, M. Castellote, N. Rafai, P. Rougeau, Which tool for durability evaluation as regards chloride ingress into concrete? Part I : comparison various method for assessing the chloride diffusion coefficient of concrete in saturated conditions, Third RILEM workshop on Testing and Modelling the chloride Ingress into Concrete, 2002, pp. 105-136.

[66] L. Trotignon, V. Devallois, H. Peycelon, C. Tiffreau, X. Bourbon, Predicting the long term durability of concrete engineered barriers in a geological repository for radioactive waste, Phys. Chem. Earth 32 (2007) 259-274.

[67] V.Q. Tran, The Contribution Toward Understanding of Mechanisms of Depassivation of Steel in Concrete Exposed to Sea Water: Theory and Thermochemical Modeling, Ecole Centrale de Nantes, 2016 Ph.D. thesis (in French).

[68] A. Soive, V.-Q. Tran, External sulfate attack of cementitious materials: new insight gained through numerical modeling including dissolution/precipitation kinetics and surface complexation, Cem. Concr. Compos. 83 (2017) 263-272.

[69] G.M. Anderson, D.A. Crerar, Thermodynamics in geochemistry: The equilibrium model: The equilibrium model, Oxford University Press, New York, 1993.

[70] M. Balonis, B. Lothenbach, G.L. Saout, F.P. Glasser, Impact of chloride on the mineralogy of hydrated portland cement systems, Cem. Concr. Res. 40 (7) (2010) 1009-1022.

[71] S. Goldberg, Surface complexation modeling, Reference Module in Earth Systems and Environmental Sciences, Elsevier, 2013pp. -

[72] V. Baroghel-Bouny, M. Thiéry, X. Wang, Performance-based assessment of durability and prediction of RC structure service life: transport properties as input data for physical models, Mater. Struct. 47 (10) (2014) 1669-1691.

[73] P. Henocq, J. Marchand, E. Samson, J.-A. Lavoie, Modeling of Ionic Interactions at the C-S-H Surface. Application to $\mathrm{CsCl}$ and $\mathrm{LiCl}$ Solutions in Comparison with $\mathrm{NaCl}$ Solutions, 2nd International Symposium on Advances in Concrete through Science and Engineering, Québec, Canada, 2006.

[75] C. Arya, N. Buenfeld, J. Newman, Factors influencing chloride-binding in concrete, Cem. Concr. Res. 20 (2) (1990) 291-300.

[76] A. Delagrave, J. Marchand, J.-P. Ollivier, S. Julien, K. Hazrati, Chloride binding capacity of various hydrated cement paste systems, Adv. Cem. Based Mater. 6 (1) (1997) 28-35.

[77] Q. Zhu, L. Jiang, Y. Chen, J. Xu, L. Mo, Effect of chloride salt type on chloride binding behavior of concrete, Constr. Build. Mater. 37 (2012) 512-517. 